Linköping University Medical Dissertation No. 1674

\title{
Geriatric Aspects of Frail Nursing Home Residents A Swedish cohort study
}

\section{Björn Westerlind}

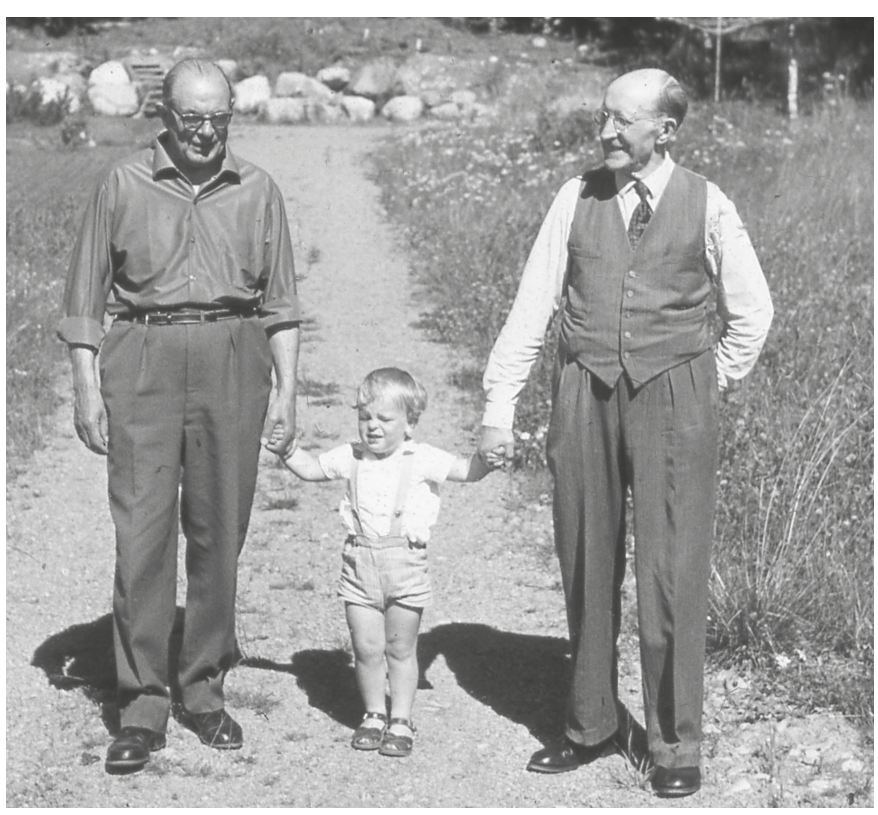


Linköping University Medical Dissertations No. 1674

\title{
Geriatric Aspects of Frail Nursing Home Residents
}

A Swedish cohort study

\author{
Björn Westerlind
}

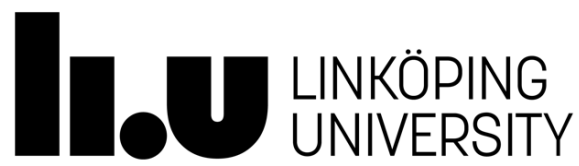

Department of Clinical and Experimental Medicine Division of Neuro and Inflammation Sciences Linköping University, SE-581 83 Linköping, Sweden Linköping 2019 
(C) Björn Westerlind 2019

Cover: The author between his grandfathers Erik Eidering to the left (age 73), and Oskar Westerlind to the right (age 78).

Photo: Åke Westerlind, 1963.

Published articles have been reprinted with the permission of the copyright holder.

Printed in Sweden by LiU-Tryck, Linköping, Sweden, 2019

ISBN 978-91-7685-101-2

ISSN $0345-0082$ 
To all the lovely older people I met over the years in the profession and privately, who shared their life experience and life story with me.

When wisdom entereth into thine heart, and knowledge is pleasant unto thy soul;

Discretion shall preserve thee, understanding shall keep thee.

Proverbs 2:10-11

(King James Version) 



\section{CONTENTS}

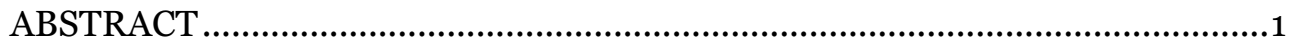

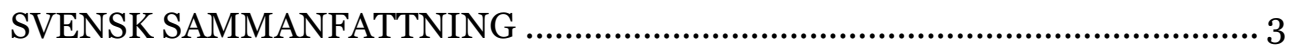

LIST OF PAPERS …………………………………....................................... 7

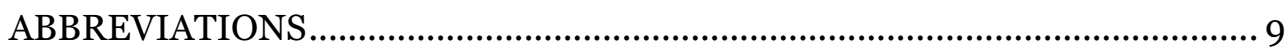

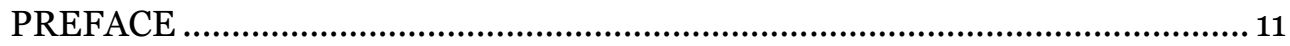

INTRODUCTION.......................................................................................13

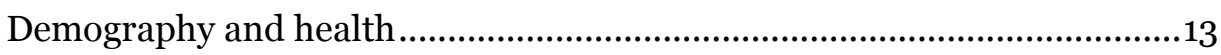

Geriatric medicine ......................................................................................14

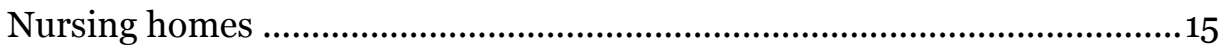

Nursing homes in Sweden...................................................................... 16

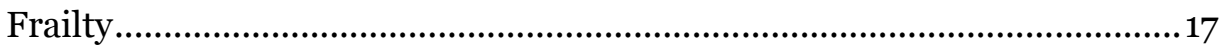

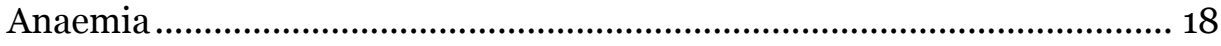

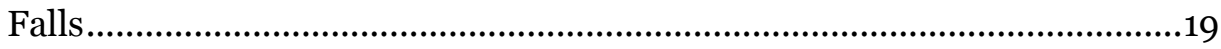

Fall risk and drugs .................................................................................... 20

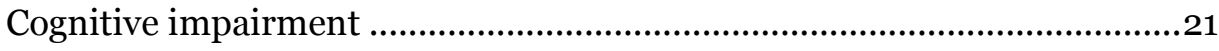

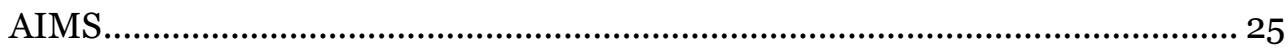

Paper I - Population characterisation and frailty ........................................ 25

Paper II - Anaemia ...................................................................................... 25

Paper III - Falls and drugs ........................................................................... 25

Paper IV - Cognitive impairment............................................................... 25

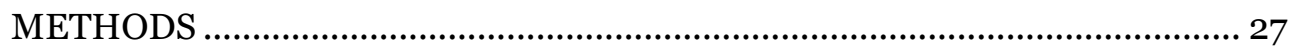

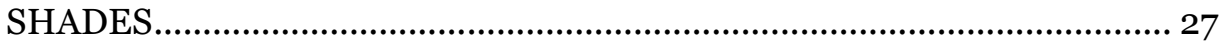

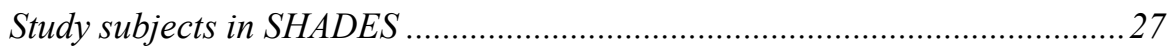

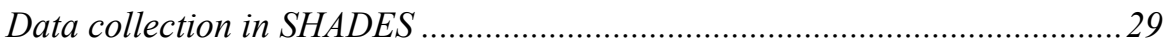

Specific methods for paper I ..........................................................................31

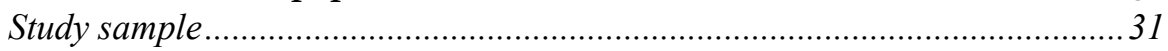

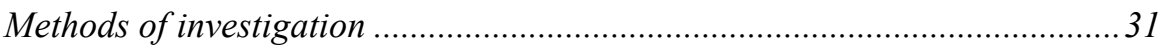

Specific methods for paper II...................................................................... 33

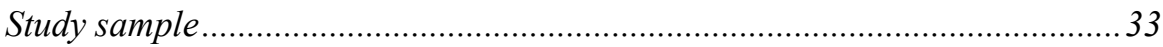

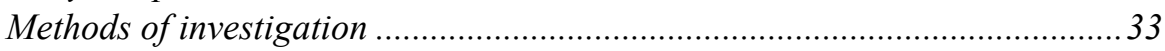

Specific methods for paper III ...................................................................... 34

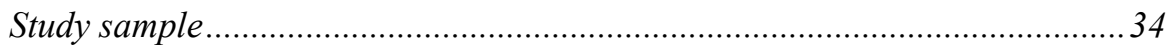




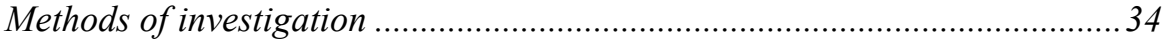

Specific methods for paper IV ........................................................................ 34

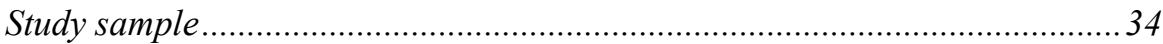

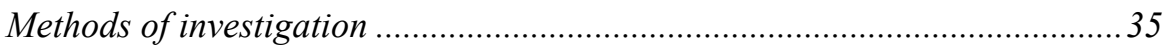

Statistical analyses ...................................................................................... 36

Ethics approval and consent to participate …….......................................... 36

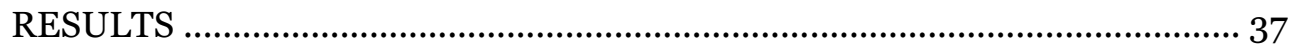

The SHADES cohort.................................................................................... 37

Population characterisation and frailty ...................................................... 37

Anaemia ................................................................................................ 39

Falls and drugs ...................................................................................41

Cognitive impairment ............................................................................. 42

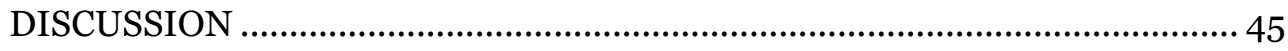

Population characterisation and frailty ...................................................... 45

Further comments on some results in paper I.............................................. 47

Anaemia ................................................................................................... 48

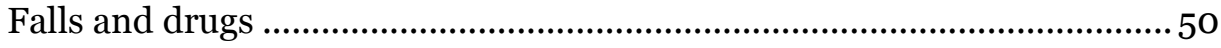

Cognitive impairment .............................................................................. 52

Methodological considerations ................................................................... 54

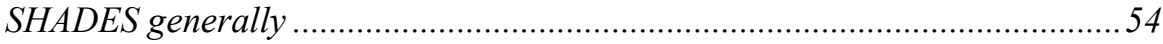

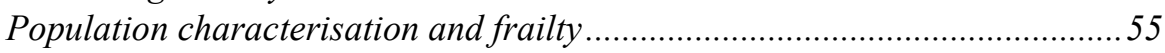

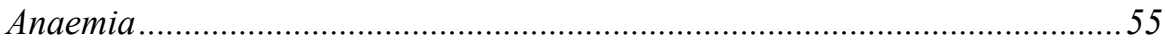

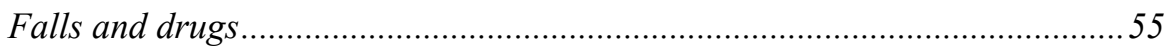

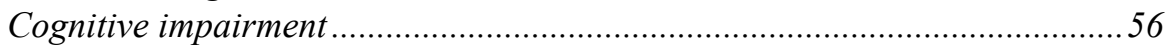

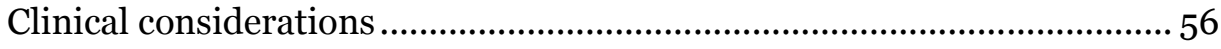

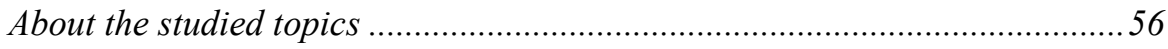

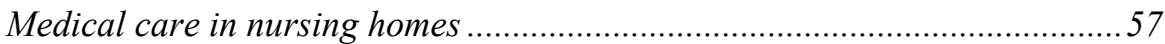

Demography and consequences for nursing homes ......................................57

Comprehensive Geriatric Assessment (CGA) …………………………….....59

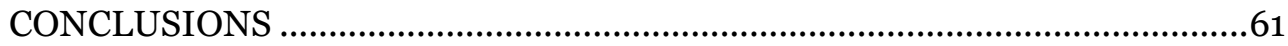

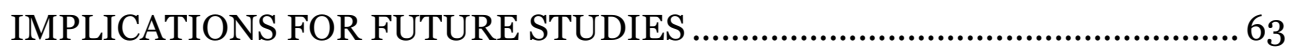

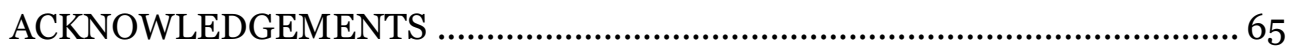

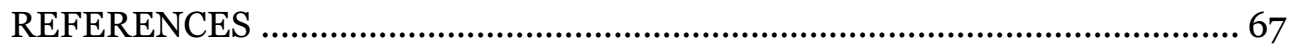




\section{ABSTRACT}

Background: The number and proportion of older people are increasing in Sweden as well as throughout the western world. Older people with increasing assistance needs that can no longer be met in their own home need institutional long-term care in nursing homes. A successive reduction of nursing home beds in combination with a future demographic development with a rapidly increasing number of older people will lead to higher demands on future medical care in nursing homes. Consequently, increased knowledge about the medical needs of nursing home residents is of great value.

Objectives: This thesis explores some important geriatric aspects of frail nursing home residents. The specific aims was to characterise the population of nursing home residents, to explore the prevalence of anaemia, paying particular attention to risk factors and mortality, to investigate associations between falls and use of possible fall risk drug classes and to estimate the prevalence of diagnostic failure of cognitive impairment and to investigate whether diagnostic failure was associated with impaired medical care.

Methods: All data originate from SHADES (the Study of Health and Drugs in Elderly nursing home residents in Sweden), a prospective cohort study that included nursing home residents at 12 nursing homes situated in three municipalities in southern Sweden between 2008 and 2011. The subjects were followed every six months with data collection from medical records concerning medications, diagnoses, hospital referrals and mortality, examinations including blood sample analyses, assessments with validated rating scales for cognitive evaluation, depression, risk of pressure ulcers, malnutrition or falls, and the need for care was rated through a questionnaire.

Results: SHADES included a total of 428 subjects with a mean age of 85 years, of whom $71 \%$ were women. They demonstrated comorbidity with a mean of three registered medical diagnoses, and polypharmacy with a mean of seven regularly used drugs. More than half of the sample (60\%) were at risk of malnutrition and one third were at risk of developing pressure ulcers. A set of single items from the performed risk assessments was found to be important in understanding frailty and need for care. One third of the women and half of the men had anaemia. For the men, anaemia was associated with significantly higher mortality. Haemoglobin decline was also associated with higher mortality. Almost everyone (93\%) had an increased fall risk and $62 \%$ had fallen during the last year. There 
was an association between falls during the last year and regular use of non-benzodiazepine hypnotics. In the older age group there was also an association between these drugs and serious falls the next 6 months. Dementia was previously diagnosed in $42 \%$. However, among subjects without a dementia diagnosis, $72 \%$ were cognitively impaired (Mini Mental State Examination <24). These subjects were significantly older, did not get anti-dementia treatment and had higher levels of brain natriuretic peptide compared to the diagnosed dementia group, possibly indicating heart failure. Their risks of malnutrition and pressure ulcers were similar to the dementia group.

Conclusions: Nursing home residents are generally frail. Anaemia is associated with higher mortality among men. The fall risk is generally high and use of non-benzodiazepine hypnotics is associated with a higher occurrence of falls. Cognitive impairment is undiagnosed in half of the cases and may indicate underlying heart failure. Consequently, regular medical follow-ups in this population are proposed to include blood count, drug review, and cognitive evaluation. In the case of cognitive impairment, exclusion of underlying disease such as heart failure should be considered. 


\section{SVENSK SAMMANFATTNING}

Antalet äldre människor ökar i Sverige liksom i hela västvärlden, både i absoluta tal och i andel av befolkningen. Med ett ökat antal äldre ökar också kraven på vård och omsorg. När äldre människor får ökande behov av hjälp och vård som inte längre kan tillgodoses i det egna hemmet, behövs dygnet-runt-vård i särskilda boendeformer (SÄBO). De senaste 1520 åren har antalet vårdplatser i SÄBO successivt minskat i Sverige. Denna minskning i kombination med ett ökat antal äldre och därtill prognoser för de närmaste 30 åren som talar för en kraftig ökning av antalet äldre kommer att förändra och öka kraven på vården i SÄBO i den närmaste framtiden. Följaktligen är en ökad kunskap om de medicinska vårdbehoven i SÄBO av stor vikt.

Denna avhandling utforskar några viktiga problemområden bland äldre personer boende i SÄBO i syfte att få ökad kunskap om hur man kan optimera vården för denna grupp. Avhandlingen består av fyra delstudier där den första delstudien beskriver den undersökta populationen ur olika aspekter med fokus på skörhet (frailty), och de efterföljande studierna fokuserar på den kliniska betydelsen av anemi, samband mellan fall och läkemedel respektive förekomsten av och betydelsen av nedsatt kognitiv funktion. Detta är mycket vanliga problemområden hos äldre personer, men har i begränsad omfattning undersökts inom gruppen äldre personer boende i SÄBO.

Samtliga ingående delarbeten bygger på data ur SHADES (the Study of Health and Drugs in Elderly nursing home residents in Sweden). SHADES var en prospektiv kohortstudie som inkluderade sammanlagt 428 äldre personer från 12 SÄBO i 3 kommuner i södra Sverige, Jönköping, Linköping och Eslöv mellan 2008 och 2011. Dessa följdes var sjätte månad med insamling av en rad data. Från journaler hämtades uppgifter om mediciner, diagnoser, sjukhusinläggningar och annat vårdutnyttjande samt dödsorsaker. De inkluderade personerna undersöktes av en forskningssköterska var sjätte månad med kontroll av bland annat vikt, blodtryck och ett antal blodprover. De bedömdes också genom ett antal etablerade skattingsskalor där kognitiv funktion, depressionssymptom, risk för fall, undernäring och trycksår samt omvårdnadsbehov värderades. 
Bland de undersökta 428 personerna var medelåldern 85 år och $71 \%$ var kvinnor. De undersökta personerna hade en samsjuklighet med i genomsnitt tre registrerade medicinska diagnoser och hade i genomsnitt 7 kontinuerliga läkemedelsordinationer. Mer än hälften av de undersökta personerna hade förhöjd risk för att utveckla undernäring och en tredjedel hade förhöjd risk för att utveckla trycksår. Några av frågorna i de utförda riskskattningsskalorna visade sig viktigast för att skatta omvårdnadsbehovet som användes som ett mått på skörhet (frailty).

En tredjedel av kvinnorna och hälften av männen hade anemi. För männen fanns ett samband mellan anemi och en förhöjd dödlighet. En sjunkande nivå av hemoglobin var också associerad med en högre dödlighet.

Nästan alla (93\%) hade en ökad fallrisk och $62 \%$ hade fallit det senaste året. Det fanns en ökad förekomst av fall under det senaste året hos de med regelbunden användning av den typ av sömnmedel som är vanligast bland äldre personer ("non-benzodiazepine hypnotics", zopiklon och zolpidem). När den undersökta gruppen delades upp i en äldre (>85 år) och en yngre grupp uppvisade de i den äldre gruppen som stod på denna typ av sömnmedel en ökad risk för allvarliga fall under de närmaste 6 månaderna.

I den undersökta gruppen hade 42 \% en känd demensdiagnos. Bland de personer som inte hade en känd demensdiagnos hade dock en betydande andel (72\%) en kognitiv nedsättning (Mini Mental State Examination <24). Denna grupp var äldre än de med diagnosticerad demenssjukdom och stod inte på demensläkemedel. De hade också i större utsträckning högre nivåer av ett ämne som stiger vid obehandlad eller underbehandlad hjärtsvikt (BNP = B-type Natriuretic Peptide) jämfört med den diagnostiserade demensgruppen, vilket kan tyda på att de även hade hjärtsvikt. Gruppen med kognitiv nedsättning utan demensdiagnos hade samma förhöjda risknivå för undernäring och trycksår som gruppen med tidigare känd demensdiagnos.

Sammanfattningsvis är de som bor i SÄBO medicinskt sköra. Anemi är vanligt och förknippad med lägre överlevnad bland män. Även ett sjunkande blodvärde är förknippat med sämre överlevnad. Fallrisken är generellt mycket hög. Regelbunden användning av den grupp sömnmedel som är vanligast bland äldre personer är förknippad med en högre förekomst av fall. Bland de äldsta som står på dessa sömnmedel regelbundet finns en ökad risk för allvarliga fallskador. Kognitiv nedsättning missas ofta och bara hälften av de med kognitiv nedsättning har fătt en demensdiagnos. 
Gruppen där kognitiv nedsättning har missats kan ha bakomliggande somatisk sjukdom såsom hjärtsvikt.

Regelbundna medicinska uppföljningar i äldreboenden rekommenderas inkludera kontroll av blodvärde, läkemedelsgenomgång och kognitiv värdering. Vid nydiagnosticerad eller nytillkommen kognitiv nedsättning bör uteslutande av bakomliggande somatisk sjukdom såsom hjärtsvikt övervägas. 


\section{LIST OF PAPERS}

I. Ernsth Bravell M, Westerlind B, Midlöv P, Östgren C J, Borgquist L, Lannering C, Mölstad S. How to assess frailty and the need for care? Report from the Study of Health and Drugs in the Elderly (SHADES) in community dwellings in Sweden. Archives of Gerontology and Geriatrics. 2011;53(1):40-5. doi:10.1016/j.archger.2010.06.011.

II. Westerlind B, Östgren C J, Mölstad S, Midlöv P. Prevalence and predictive importance of anemia in Swedish nursing home residents - a longitudinal study. BMC Geriatrics. 2016;16(1):206. doi:10.1186/s12877-016-0375-2.

III. Westerlind B, Östgren C J, Mölstad S, Midlöv P, Hägg S. Use of non-benzodiazepine hypnotics is associated with falls in nursing home residents: a longitudinal cohort study. Aging Clinical and Experimental Research. 2018 Oct 19. doi: 10.1007/s40520-0181056-o [Epub ahead of print] PMID: 30341643.

IV. Westerlind B, Östgren C J, Midlöv P, Marcusson J. Diagnostic failure of cognitive decline in nursing home residents may lead to impaired medical care. Dementia and Geriatric Cognitive Disorders. Accepted 9 March 2019. doi: 10.1159/000499671. 


\section{ABBREVIATIONS}

ADL

ATC

BNP

BMI

CGA

CRP

CSDD

DFRI

DSM

eGFR

GFR

$\mathrm{Hb}$

ICD

MNA

MNA-SF

MMSE

Nt-proBNP

SHADES

SNAC

SSRI

STOPP

TSH

WHO
Activities of Daily Living

Anatomical Therapeutic Chemical classification system

B-type Natriuretic Peptide

Body Mass Index

Comprehensive Geriatric Assessment

C-Reactive Protein

Cornell Scale for Depression in Dementia

Downton Fall Risk Index

Diagnostic and Statistical Manual of Mental disorders

estimated Glomerular Filtration Rate

Glomerular Filtration Rate

Haemoglobin

International Classification of Diseases

Mini Nutritional Assessment

Short-Form of Mini Nutritional Assessment

Mini Mental State Examination

N-terminal pro B-type Natriuretic Peptide

The Study on Health and Drugs in Elderly nursing home residents in Sweden

Swedish National Study of Aging and Care

Selective Serotonin Reuptake Inhibitors

Screening Tool of Older Person's Prescriptions

Thyroid-Stimulating Hormone

World Health Organization 


\section{PREFACE}

I have had an attraction to older people since I was a child. One reason may be my childhood experiences, as I grew up as a single child with many older people around me. My grandparents became important persons in my early years. From the age of 6 , our family had a summer cottage out in the countryside. On the other side of a raspberry hedge and a gravel road, three older sisters also lived during the summer, each one in their own small red summer cottage, and they quickly became my friends. Overall, I can remember several older people of importance for my personal development from my early years.

As a young doctor during my internship, I did my primary care placement at a health centre with many older patients in the catchment area. These grateful older patients were a main reason why I then chose my specialist training to become a primary care physician.

It was for these older patients that I felt I could do the most. They were sicker, they were more dependent on me as a doctor and on my advice, and they were thankful and encouraging. And at the same time, they had exciting life stories. I really enjoyed getting to know my older patients.

Therefore, after some years in primary care, the step to geriatrics was a logical one, and close to my heart. As a geriatrician I could focus on the fragile older patients whose needs often risk being neglected in the health care system. Furthermore, my experience from my time as a general practitioner was a benefit in the complexity of the older patients I met as a geriatrician. I was however no longer controlled by a reception journal. And I was even more challenged by the many needs of older people.

Geriatrics contains medical challenges, but is also a delicate balance between different ethical dilemmas. It includes some areas where you as a doctor may feel that you cannot do that much in concrete medical terms in relation to many other medical conditions. But geriatrics is aimed at a group where it is particularly important that the care is compassionate and that the care provider is willing to listen and trying to understand. 
My research interest goes back a long time. My first research course was in 1990-91. Different professional and private circumstances have meant that it has taken time for me to get on with my research wish, while at the same time I have not been able to drop the idea of moving forward with research as I gained more experience in the geriatric field.

When I look back on a long journey towards this thesis, I see that the circle has been closed. Throughout my medical career, I have been fascinated by working with breadth and complexity. Furthermore, the attraction to older people is still there. I can now see that my research also has that focus, with the difficulties, challenges and shortcomings that this entails. 


\section{INTRODUCTION}

\section{Demography and health}

The numbers of older people are increasing rapidly, both in Sweden and globally [1]. In 2017 about half a million people in Sweden were older than 80 years. The number of 80 -year-olds has doubled since 1980 , and is forecast to double again even faster by 2050 [2]. This demographic development is due to larger birth cohorts in the 1940 os and increasing life expectancy. In 90-year-olds, the historic increase is even more evident. For this cohort prognoses are more uncertain, but the increase is expected to be even greater, and this group may have tripled by 2050 (Figure 1).

Figure 1 Demographic history and prognosis in Sweden 1970-2070

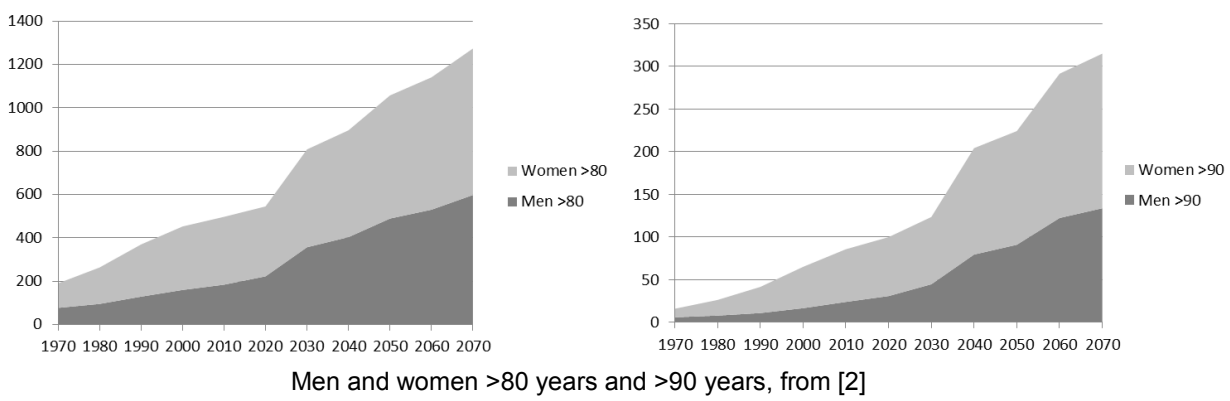

The demographic trends are similar, with some variations, in the European Union. The ageing of European populations presents health care and welfare systems with new challenges, but also has significance for the future needs of long-term care [3]. However, considerable uncertainty remains about health trends among the oldest old [4].

In recent decades, a number of theories have attempted to describe the interplay of mortality and morbidity patterns with demographic changes in the older population cohorts. The theory of expansion of morbidity described how a decrease in mortality entailed an increase in morbidity [5, 6]. In contradiction, the theory of compression of morbidity claims that disease prevention results in a more rapid increase in healthy years than in total life expectancy $[7,8]$. A third theory, the concept of a dynamic equilibrium, combines parts of these theories and states that an equilibrium between morbidity and mortality keeps the proportion of healthy years more or less constant [9]. 
It seems that, although disability measures in older people tend to show improvement, there is a simultaneous increase in chronic diseases and functional impairments [4]. Consequently, the future need for social services and long-term care may not be in line with demographic projections. The future need for long-term care is also influenced by several other factors such as health promotion, disease prevention, support for self-care, availability of informal care and technical developments [3, 10]. In parallel with an ageing population, there has been a reduction in hospital beds over time in most OECD countries. This development is also seen in Sweden, which today has fewer hospital beds than comparable countries [11].

A large proportion of today's 85-year-olds show good levels of self-rated health, and have low utilization of healthcare service and a limited need for social support despite comorbidity $[12,13]$. Nevertheless, an increasing proportion of older people undoubtedly means higher demands on health and social care, which is a challenge for most countries in the future.

\section{Geriatric medicine}

Geriatrics or geriatric medicine is the medical specialty that deals with morbidity in older people. Modern geriatrics is sometimes considered to have been born with the invention of the word "geriatrics" by the Austrian-born New York physician Ignatz Leo Nascher in 1909. In a letter to the New York Medical Journal [14] he suggested:

Geriatrics, from geras, old age, and iatrikos, relating to the physician, is a term I would suggest as an addition to our vocabulary to cover the same field that is covered by the term pediatrics in childhood... to emphasize the necessity of considering senility and its diseases apart from maturity and to assign it a separate place in medicine.

Nascher then developed the concept a few years later in his book "Geriatrics. The Diseases of Old Age and their Treatment" [15], in which the foreword states:

In presenting this work to the medical profession the author hopes to arouse an interest in geriatrics and stimulate research into the causes of senescence and the pathology of senile diseases. It is not too much to expect that as a result of such interest and research we will get a better knowledge of the senile organism and be more successful in coping with senile diseases than we are at present.

Reading Nascher's book today gives an indication of a tremendous development in terms of knowledge and attitudes towards older people in gen- 
eral and the morbidity of older people in particular during the last 100 years.

Bernard Isaacs (1924-1995) was a later, and at the time world-leading, geriatrician who coined the concept of "giants of geriatrics" in 1965 [16]. Isaacs evolved the concept during the following years [17], and in his last book in 1992 he expanded the original "giants of geriatrics", i.e. instability, immobility, incontinence and impaired intellect/memory, with five others, namely stroke, aphasia, visual impairment, auditory impairment and depression [18]. He also suggested some features of what these "giants of geriatrics" have in common:

\section{Common features of the "giants of geriatrics" [18] \\ - Multiple causation \\ - Chronic course \\ - Deprivation of independence \\ - No simple cure}

Other authors have proposed new "giants of geriatrics", and frailty is nowadays often considered one of them [19, 20]. Other candidates recent suggested include sarcopenia [19] and poor oral health [21].

In older people, common medical conditions often have atypical presentations. Symptoms in geriatric patients may be general, vague and insidious, and therefore hard to distinguish from normal ageing. Symptoms may be altered from what is normally expected. Furthermore, comorbidity and ageing may further obscure the clinical presentation and make correct interpretation and diagnosis difficult.

\section{Nursing homes}

Increasing numbers of older adults worldwide highlight the need for longterm care services [22]. Countries in Europe have adopted very different policies in relation to long-term care, partly suggesting different views of the role of the state and the family [3]. Furthermore, experts disagree about recent trends in the size of the older institutionalized population [23]. An international survey has also revealed international differences in the terminology used to describe "nursing homes", and found considerable variances in physicians' regular visits [24]. Since the definition of a nursing home and the type of assistance provided in a nursing home vary considerably by country, the following definition is proposed [25]: 
A nursing home is a facility with a domestic-styled environment that provides 24-hour functional support and care for persons who require assistance with ADL (activities of daily living) and who often have complex health needs and increased vulnerability.

\section{Nursing homes in Sweden}

In Sweden, institutional long-term care was reorganized in 1992 through "Ädelreformen". The responsibility for all institutional long-term care was then moved from the county council to the local municipalities. Since this reform, the total number of beds in long-term care for older people has decreased and home care has increased. During recent decades an increasing share of institutional care is privately run, with a figure of about $20 \%$ in 2015 [26]. However, the funding and supervision of all elderly care in Sweden is still a responsibility for the municipalities. Physicians employed within the primary care system regularly visit the nursing homes.

Institutional long-term care can be specialized in dementia care and may offer different levels of health and social care support. In the Study on Health and Drugs in Elderly nursing home residents in Sweden (SHADES), as well as throughout this thesis, "nursing homes" refers to permanent institutional long-term care that provides 24-hour functional support and care for persons who require assistance with ADL, including dementia care units. The term "community dwellings", used in paper I, is to be considered synonymous with the term "nursing homes" used in the subsequent papers.

Table 1 Nursing home beds in Sweden

\begin{tabular}{|lcccc|}
\hline Year & 2000 & 2005 & 2010 & 2015 \\
\hline Nursing home beds & 121000 & 100000 & 91000 & 82000 \\
\hline $\begin{array}{l}\text { Proportion }>65 \text { years living in } \\
\text { nursing homes }\end{array}$ & $8 \%$ & $6 \%$ & $5 \%$ & $4 \%$ \\
\hline $\begin{array}{l}\text { Proportion }>80 \text { years living in } \\
\text { nursing homes }\end{array}$ & $21 \%$ & $17 \%$ & $14 \%$ & $13 \%$ \\
\hline
\end{tabular}

Data from [26-29]

In 2015 there were 82000 individuals living permanently in nursing homes in Sweden [26]. 4\% of those aged 65 or older, and $13 \%$ of those aged 80 or older lived in a nursing home. This can be compared to 2000, when 121 ooo persons older than 65 years $(8 \%)$ lived permanently in different forms of institutional care [27]. The decreasing proportion of the 
older population living in nursing homes in Sweden over several years (Table 1) [26-29] implies that nursing home residents in Sweden today are older, with more comorbidity and frailty, and are in greater need of care and services compared to previously. In Norway, a similar development has been shown to lead to a higher occurrence of cognitive impairment and more severe dementia in nursing home residents over time [30].

Nursing home research features specific difficulties and challenges, and there is considered to be a paucity of high quality research in nursing homes [31]. Furthermore, research in nursing home facilities in Sweden is limited, especially with a longitudinal approach. SHADES was designed to include various aspects of ageing in a frail nursing home population.

\section{Frailty}

Frailty, suggested as a new "geriatric giant" [19, 20], is a geriatric syndrome that has been given increased attention in recent decades. The first scientific use of the term was 40 years ago [32]. Frailty is generally considered as a state of vulnerability in an older person with increased risk of adverse outcomes such as falls, functional deterioration or disability, hospitalization and mortality $[19,20]$. Over the years there has been an ongoing debate on how to define and measure frailty. As an example, two consensus efforts with leading experts in the field were performed in 2013 $[33,34]$, but without achieving an operational definition. More than 40 operational definitions have been proposed [20]. Nevertheless, three major frailty models have been suggested: the physical frailty model, the deficit accumulation model of frailty, and the biopsychosocial or multidimensional model.

The physical frailty model was proposed by Fried et al. [35] and provided an early potential standardized definition of frailty as a clinical syndrome in which three or more of five criteria (unintentional weight loss of $10 \mathrm{lbs}$ in the past year, self-reported exhaustion, weakness measured by grip strength, slow walking speed and low physical activity) were present.

The deficit accumulation model is an alternative early attempt to describe or define frailty proposed by Rockwood et al. [36]. The extensive 70-item Canadian Study of Health and Aging (CSHA) Frailty Index focuses on accumulation of clinical deficits, and includes several lost abilities in ADL and presence of diseases. The seven-step CSHA Clinical Frailty Scale is further developed to be a more clinically useful grading of frailty, focusing 
on function and not physical performance. An early comparison between these two instruments and the proposed definition by Fried [35] in a nursing home population concluded that no instrument was superior and the definition of frailty was still considered a challenge [37].

The biopsychosocial or multidimensional model has gained increased attention during the past decade as a third major approach to frailty. This model mixes physical and psychosocial domains, and expands the concept of frailty toward social sciences [38, 39].

Numerous assessment instruments or rating scales have been developed due to the lack of general consensus. A recent review identified a total of 67 frailty assessment instruments used in research articles [40]. Of these, nine were highly cited ( $\geq 200$ citations) and the instrument Physical Frailty Phenotype (PFP), also called Cardiovascular Health Study (CHS) frailty phenotype, based on the early suggested definition by Fried in 2001 [35], was still by far the most cited one in research articles.

Both Fried and Rockwood pointed out early on that frailty is a concept that is different from multi-morbidity or disability, and this fact is still considered a consensus.

\section{Anaemia}

Anaemia is not among the "giants of geriatrics" originally described by Isaacs, but meets three of the four features later suggested by Isaacs for what the "giants of geriatrics" have in common [18]. Anaemia is common in older people and its prevalence increases with advancing age [41-44]. Anaemia in older adults is frequently associated with negative outcomes, including decreased physical performance, increased number of falls, increased frailty, increased hospitalization, increased cognitive impairment and increased mortality [45].

There is however some debate about the definition of anaemia. Anaemia is usually defined according to the World Health Organization (WHO) definition as haemoglobin $(\mathrm{Hb})<120 \mathrm{~g} / \mathrm{L}$ in women and $<130 \mathrm{~g} / \mathrm{L}$ in men [46]. These WHO limits were set by an expert panel in 1968, but probably without an intention to set a gold standard for all to follow in the future. The definition was suggested at a meeting on nutritional studies. It was given with rough limits without decimals, there were few references supporting those limits, and furthermore there was a small number of reference subjects and several methodological issues [47]. In particular, the 
relevance of the WHO limits in older people has been debated since the reference sample was aged $<65$ years [48].

Several factors may influence which levels of $\mathrm{Hb}$ are to be considered as anaemia in older people. It has been suggested that lower anaemia limits for older people in general are motivated as a consequence of ageing itself [49]. Moreover, in older populations, it has been suggested to use similar limits for men and women $[49,50]$. If lower $\mathrm{Hb}$ limits in premenopausal women are motivated due to menstrual blood losses, these could consequently be questioned in older women [51]. On the other hand, higher levels of androgens in men, with clinically important gender differences persisting in older ages, stimulate the hematopoietic system by various mechanisms and are correlated with a higher $\mathrm{Hb}$ level [52]. When using the WHO limits, older men have a higher prevalence of anaemia than women, as a result of the sex-specific limits [53]. Still, despite being debated, the WHO limits are the most commonly used limits in epidemiological studies and have also been found to be appropriate and clinically relevant by several authors for older persons [42, 48, 54].

Several authors emphasize that anaemia is not a consequence of normal ageing but a marker of disease and associated with increased mortality $[50,54,55]$. Some previous studies indicate that anaemia is a stronger risk factor for mortality in older men than in women $[48,54]$, and this is indicated even for mild anaemia [56]. The main causes of anaemia in older people are nutrient-deficiency-related anaemias, anaemia due to chronic disease or chronic inflammation and anaemia due to chronic kidney disease, but there is also a high rate of unexplained anaemia $[41,53]$. Chronic kidney disease has been highlighted as an important cause of anaemia in nursing home residents [57-60].

However, few studies have been performed on the consequences of anaemia in nursing home residents. A systematic review from 2008 [42] found that only four out of 45 studies on anaemia in older persons had been carried out on a nursing home population. The need for more research in the area of anaemia in older people is pointed out by several authors [41, 42, $61]$.

\section{Falls}

Instability is one of the original "giants of geriatrics" described by Isaacs [16-18]. Falls and fall-related injuries are common and well-documented among older people, and constitute a major cause of pain, disability, loss 
of independence and premature death [62]. Several risk factors for falls in older people have been identified. These include increasing age [62], reduced mobility [63], previous falls [63], cognitive impairment [63-65], anaemia [66] and medication use [62, 63].

Falling is more frequent among older people who are living in nursing homes than in those who are living in community [62], but prevention strategies are hard to evaluate due to multiple confounding factors [63]. For older people, the number of medications is associated with increased fall risk [67]. Minimization of drug use, and especially reduction of psychotropic medication, is therefore included in fall prevention recommendations [63].

\section{Fall risk and drugs}

Several factors contribute to the challenge of the pharmacological treatment of older people. Such factors include comorbidities and chronic conditions often requiring multiple medications [67, 68], increased sensitivity to drug effects due to age-related physiological changes [69] and limited evidence of drug effectiveness and safety in older and frail patients [70].

Inappropriate medication of older people has been an area of increased focus for Swedish authorities [71-74] as well as internationally in recent decades. The development and gradual updating of instruments like Beers Criteria, developed in the US [75-79], and STOPP (Screening Tool of Older Person's Prescriptions) Criteria, developed in Europe [80, 81], aim to find criteria to evaluate the medication of older people and to avoid potentially inappropriate prescribing. In these instruments, fall riskincreasing drugs have been identified. Beers Criteria lists drugs and drug classes that are potentially inappropriate for older people with a history of falls or fractures, and STOPP Criteria list drugs that increase the risk of falls in older people. These lists include several psychotropic drug classes, such as benzodiazepines [76-81], tricyclic antidepressants [77-79], selective serotonin re-uptake inhibitors (SSRI) [78, 79], antipsychotics [78-81] and anticonvulsants $[78,79]$. The recent versions of these instruments also include non-benzodiazepine hypnotics [78, 79, 81]. Among cardiovascular drugs, STOPP Criteria include vasodilators [80, 81], and an earlier version of Beers Criteria included beta-blockers [76]. A generally held list of fall risk-increasing drugs is included in recommendations from the Swedish National Board of Health and Welfare and includes several cardiovascular and psychotropic drug groups [73, 74]. 
Furthermore, some reviews and meta-analyses of medications associated with falls in older people also highlight different psychotropic drug classes as fall risk-increasing drugs, mainly benzodiazepines [82, 83], antidepressants [82-84] and sedatives/hypnotics [83, 84]. In one of these reviews, an elevated fall risk related to the use of antipsychotics was indicated [82]. However, this has been questioned in more recent reviews [83, 84]. Whether fall risk is associated with cardiovascular or antihypertensive drugs has been reported as uncertain in these reviews [82-84].

Despite the fact that the nursing home population has a high fall risk, few recent studies focus on associations between drug use and fall risk in nursing homes. However, the use of psychotropic drug classes such as antipsychotics [85-87], antidepressants [85] and benzodiazepines [86, 87] is associated with fall risk in nursing homes. Non-benzodiazepine hypnotics, considered to be well tolerated in older people [88], usually recommended for insomnia in older people [73, 89, 90], and more often used in nursing homes than in home environments [91], are reported to be associated with an elevated risk of hip fractures in one nursing home study [92]. This study was performed in the US, with different prescription options and traditions within the group of non-benzodiazepine hypnotics than in Europe. Furthermore, the studied nursing home population was younger (age $\geq 50$ years, mean age 81) than most nursing home populations.

\section{Cognitive impairment}

Cognitive impairment is another one of the original "giants of geriatrics" described by Isaacs [16-18]. Dementia incidence and prevalence increases exponentially with ageing. The prevalence is often generally estimated as being around $10 \%$ in 80 -year-olds, and about $40 \%$ in 90-year-olds in Europe including Sweden [93]. Several studies indicate a decreasing agespecific dementia incidence [94-97] and prevalence [98, 99] in high income countries, which is believed to be influenced by cardiovascular prevention and larger cognitive reserve due to a higher educational level. However, there are also some conflicting results [100, 101], and a recent review found no evidence to suggest a revision of current age-specific dementia prevalence assumptions [102]. Several previous studies have shown that dementia is generally underdiagnosed [103, 104].

Cognitive decline constitutes a major predictor for long-term care use [105]. The estimated frequency of dementia or cognitive impairment in long-term care populations varies between studies in different countries and may partly be influenced by cultural factors. A systematic review reports a median prevalence of $58 \%$, but in this review there was a consid- 
erable variation in prevalence (12\%-95\%) as well as in sample sizes and diagnostic instruments used [106]. A report from the European Commission estimates that approximately $80 \%$ of patients in long-term care suffer from cognitive decline or a diagnosed progressive memory disorder [105]. A study performed in nursing homes in seven European countries and Israel reports a 70\% prevalence of cognitive decline [107].

The Swedish National Board of Health and Welfare has previously estimated that $70 \%$ of residents in Swedish nursing homes may suffer from dementia [108]. A recent study in a Swedish sample of nursing homes found cognitive impairment in $67 \%$ [109], but in that study cognitive assessment was carried out through a questionnaire to the nursing home staff and not a cognitive test performed by the nursing home resident. In a recent Norwegian study, cognitive investigation on admission to nursing homes found dementia in $84 \%$ [110]. Previous studies have reported that cognitive impairment is underdiagnosed in nursing homes, exemplified by nursing home studies in Scotland [111] and Austria [112] that found cognitive impairment in a total of $90 \%$ and $85 \%$ respectively, of which about one third was previously unknown. Undiagnosed dementia has several consequences such as absent anti-dementia drug treatment, less awareness of possible inappropriate drugs, inferior interaction and understanding between residents and caregivers, and has prognostic implications [113].

The Mini Mental State Examination (MMSE) is widely used as a screening tool for cognitive impairment [114]. MMSE assesses cognitive function through a number of questions directed to the patient. Scores range from o to 30 , with a score $<24$ generally used to raise a suspicion of cognitive impairment [115]. However, very recently a higher MMSE cut-off at $\leq 26$ has been suggested for older persons up to the age of 93 [116]. Consequently, an MMSE cut off of <24 may be a conservative MMSE value to indicate cognitive impairment in these populations.

Few studies have studied the impact of un-noted cognitive impairment on medical care in other aspects. One study found that pain was more prevalent among cognitively impaired nursing home residents with dependency in ADL [109], but another study found that residents without dementia had more pain than patients with dementia [110]. Previous communitybased studies have shown a negative association between cognitive function and levels of N-terminal pro B-type natriuretic peptide (NT-proBNP), which is used as a marker of heart failure in clinical practice [117-119]. 
Furthermore, dementia and cognitive impairment are related to an increased risk of malnutrition [120]. 


\section{AIMS}

The aim of this thesis was to explore some important geriatric aspects of frail nursing home residents using the SHADES population.

\section{Paper I - Population characterisation and frailty}

The aim of paper I was to characterise the population of nursing home residents, to describe morbidity, use of drugs and risk of severe conditions such as malnutrition, pressure ulcers and falls, and to explore associations between these variables and frailty as determined by functional limitations and somatic and psychological symptoms.

\section{Paper II - Anaemia}

The aim of paper II was to explore the prevalence of anaemia in a nursing home population, paying particular attention to risk factors and mortality associated with anaemia or $\mathrm{Hb}$ decline.

\section{Paper III - Falls and drugs}

The aim of paper III was to investigate associations between falls and use of possible fall risk-increasing drug classes including non-benzodiazepine hypnotics in older people living in nursing homes in relation to age groups.

\section{Paper IV - Cognitive impairment}

The aim of paper IV was to estimate the prevalence of diagnostic failure of cognitive impairment in a sample of Swedish nursing home residents and to investigate whether diagnostic failure was associated with impaired medical care. 


\section{METHODS}

Papers I-IV were all based on the longitudinal cohort study SHADES.

\section{SHADES}

The Study on Health and Drugs in Elderly nursing home residents in Sweden (SHADES) was a longitudinal cohort study of older people living in 12 nursing homes in three municipalities in the south of Sweden (five in Jönköping, four in Linköping, and three in Eslöv). The selected nursing homes were all in the public sector. The study was planned during 20062007, and data were collected during 2008-2011. The general aim of SHADES was to describe and analyse mortality, morbidity, health conditions and drug use among older people living in nursing homes, and to use the results to provide a better basis for improved and individualbased care for the older people in nursing homes and for the planning of interventions to improve health, optimize use of drugs, and decrease the need for acute hospital care.

Figure 2 Inclusion of study subjects in SHADES

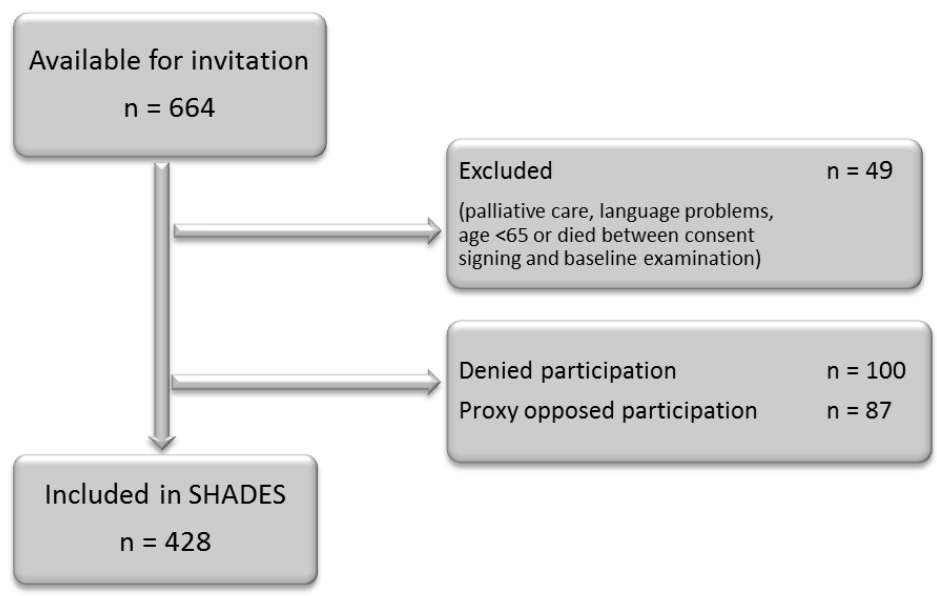

\section{Study subjects in SHADES}

All residents living in the 12 nursing homes were considered for participation. However, those living in a nursing home only temporarily for palliative care or short-term rehabilitation were excluded, as well as individuals 
with language difficulties and persons under the age of 65 . When a resident living in one of the nursing homes moved or died, the next person who moved into the nursing home was considered for participation. During 2008-2011, a total of 664 were available for inclusion and 428 individuals were included. At inclusion 49 were excluded for various reasons, 100 refused to participate and a proxy denied participation for 87 (Fig. 2)

\section{Figure 3 Inclusion and failure in SHADES}

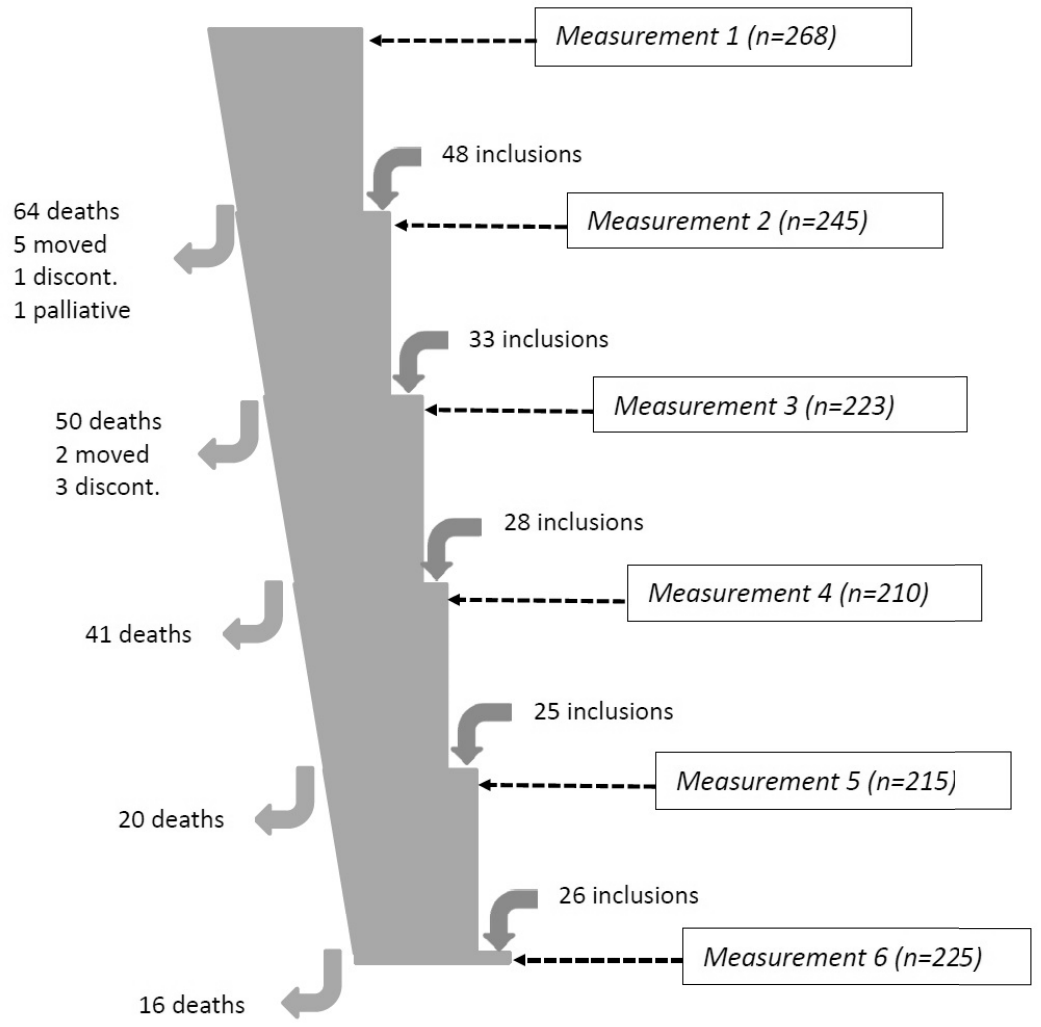

Included subjects were examined every 6 months ( \pm 1 month). As participants were included during the whole study period (Fig. 3), the participants had varying numbers of follow-up assessments (Table 2). 
Table 2 Study subjects participating in the follow-up assessments

\begin{tabular}{|cccc|}
\hline Assessment number & Total subjects & Women & Men \\
\hline 1 & 428 & 305 & 123 \\
\hline 2 & 331 & 234 & 97 \\
\hline 3 & 256 & 181 & 75 \\
\hline 4 & 192 & 137 & 55 \\
\hline 5 & 156 & 112 & 44 \\
\hline 6 & 116 & 83 & 33 \\
\hline
\end{tabular}

\section{Data collection in SHADES}

Data were collected by three experienced nurses, one from each municipality, who were engaged part-time as study nurses. To ensure data quality, these study nurses were trained in the study methods before the start of the study and at regularly held study meetings to strive for consistency in the assessments and performance. Study subjects were examined at baseline and every 6 months ( \pm 1 month) during the study period. The study nurses gathered information about the study subjects from the staff such as information about the date of the move to the nursing home, decisions from social services, and the estimated weekly time for physical and social activities. Furthermore, the study nurses collected information from patient records on current drug use, diagnoses and health care utilization.

Regular drugs were considered to be the drugs the patient was prescribed for continuous use on the day of data collection, whereas drugs taken as needed were not registered. Regular drugs were registered with codes according to the WHO Anatomical Therapeutic Chemical (ATC) classification system [121] and classified in drug classes. The number of regularly used drugs was calculated for each subject. The number of psychotropic drugs, defined as antipsychotics (ATC code No5A), anxiolytics (No5B), sedatives (No5C) and antidepressants (No6A), was calculated for each subject (papers III-IV).

Diagnoses were collected with diagnosis codes according to the Swedish version of the International Classification of Diseases (ICD) 10th version [122]. Dementia was defined as any of the following ICD codes: Foo dementia in Alzheimer's disease, Fo1 vascular dementia, Fo2 dementia in other diseases classified elsewhere, Fo3 unspecified dementia, or G30 Alzheimer's disease. 
The in-person testing of study subjects was performed by the study nurses with assistance from the staff at the nursing home, and included measurements of weight and height as a basis for later calculation of body mass index (BMI). Blood pressure was measured three times at 1-minute intervals in the right arm, while in a sitting position, and the mean value of the three measurements was used.

MMSE [114] was used to measure cognitive function. MMSE assesses cognitive function through a number of questions directed to the participant regardless of cognitive function, and scores range from o to 30 . In paper I values $\leq 24$ were considered to indicate cognitive dysfunction, but in papers III-IV values <24 were considered to indicate cognitive impairment. The Cornell Scale for Depression in Dementia (CSDD), in SHADES based solely on information from staff members, was used to assess depressive symptoms [123].

Several risk assessments based on interviews with the nursing home staff with good knowledge of the resident were performed. The Downton Fall Risk Index (DFRI) [124] was used to assess fall risk. The Modified Norton Scale (MNS) [125] was used to assess the risk of developing pressure ulcers, and the Short-Form Mini-Nutritional Assessment (MNA-SF) [126] was used to assess the risk of malnutrition. A questionnaire previously used by the Swedish National Study of Aging and Care (SNAC) [127] was performed, with 25 questions to the nursing home staff concerning ADL, need for care and various symptoms.

Fasting venous blood samples were drawn according to a standard procedure. B-Hb and p-glucose, and in the case of a history of diabetes HbA1c as well, were analysed in connection with the sampling at the local laboratories of the hospitals in Jönköping and Linköping and the health centre in Eslöv. Remaining blood samples were stored at $-70^{\circ} \mathrm{C}$ in a freezer and were analysed later on at the laboratory at Ryhov County Hospital in Jönköping for creatinine, cystatin C, B-type natriuretic protein (BNP), transthyretin, C-reactive protein (CRP), ferritin, transferrin, thyroidstimulating hormone (TSH), cobalamin, folate and 25-hydroxyvitamin D3. Unless otherwise stated, the routine cut-off values suggested by the laboratory were used. For assessing renal function, the formula for estimating glomerular filtration rate (GFR) according to Swedish guidelines was used [128]. Furthermore, bacterial specimens for cultivation from urine, the rectal mucosa, the groin and active skin lesions were collected serially by the study nurse on location between March 2008 and September 2010 . 
The subjects were monitored during a follow-up period of up to 7 years after inclusion with death dates from the Swedish population register.

All data were entered in a database by an experienced central project administrator with a background as a research nurse, and all original data were also stored in paper form at Futurum - Academy of Health and Care, Jönköping.

\section{Specific methods for paper I}

\section{Study sample}

The study sample in paper I consisted of the first 315 subjects included in SHADES.

\section{Methods of investigation}

Baseline data about the numbers of diagnoses and drugs, the most frequently occurring diagnoses and drug classes, systolic and diastolic blood pressure and measurements of $\mathrm{B}-\mathrm{Hb}$ and P-glucose were all used as health indicators. The results from MMSE and CSDD were used as indicators of cognitive function and mood respectively. These baseline analyses/health indicators were used together with the risk assessment scales DFRI, MNS and MNA-SF to describe the population including gender differences using descriptive statistics (students T-test, chi-square test).

Table 3 Extractions from the three risk assessment scales

\begin{tabular}{|ll|}
\hline Extraction and included items & \\
\hline Physical ability & Sensory function \\
MNS physical activity & DFRI unsecured walk \\
MNS motor ability & DFRI sensory deficiency \\
\hline MNA motor skills & DFRI vision deficiency \\
DFRI motor deficiency & DFRI hearing deficiency \\
DFRI walking ability & MNS incontinence \\
\hline Psychological/cognitive function & Use of drugs \\
MNA neuropsychological item & DFRI no drugs \\
DFRI oriented & DFRI sedative drugs \\
MNS psychological status & DFRI use of hypertension drugs \\
\hline DFRI use of Parkinson disease drugs & DFRI other drugs \\
DFRI use of antidepressive drugs & DFRI having fallen \\
\hline Nutritional status & \\
MNS food intake & \\
MNS fluid intake & \\
MNS general physical condition & \\
MNA BMI & \\
MNA decrease in food intake & \\
MNA disease in 3 months & \\
MNA loss of weight & \\
\hline
\end{tabular}


The second aim of the paper, to analyse associations of baseline data and risk assessments with "frailty and need for care" was performed in several steps. In an attempt to simplify the risk assessment scales a factor analysis with Varimax rotation was performed. It included all the items in MNS (seven items), DFRI (11 items/16 questions) and MNA-SF (six items) and converged into five extractions (Table 3 ).

As the outcome variable "frailty and need for care" the 25 items of SNAC was used. For these items, another factor analysis with Varimax rotation was performed which resulted in three categories (Table 4). The weighted scores for each of these outcome categories were used together with the total SNAC score as outcome variables.

Table 4 Categories from the $\mathbf{2 5}$ outcome variables of SNAC

\begin{tabular}{|llc|}
\hline Categories & Included items & Points (x weight) \\
\hline Functional problems or disabilities & Cleaning/housework & $0-2(x 2)$ \\
& Cooking & $0-2(x 2)$ \\
& Shopping & $0-2(x 2)$ \\
& Transportation & $0-2(x 2)$ \\
& Doing laundry & $0-2(x 2)$ \\
& Eating & $0-2(x 2)$ \\
& Bathing & $0-2(x 2)$ \\
& Dressing & $0-2(x 2)$ \\
& Toileting & $0-2(x 2)$ \\
& Moving from bed to chair & $0-2(x 2)$ \\
\hline Somatic symptoms & Urine incontinence & $0-3(x 1)$ \\
(Sum $\mathbf{0 - 4 6}$ points) & Faeces incontinence & $0-3(x 1)$ \\
& Vision problems & $0-3(x 1)$ \\
& Hearing problems & $0-3(x 1)$ \\
& Pain & $0-3(x 1)$ \\
& Dizziness & $0-3(x 1)$ \\
& Physical problems & $0-3(x 6)$ \\
& Urine catheter & $0-1(x 1)$ \\
& Pressure ulcer & $0-1(x 3)$ \\
Psychological/cognitive symptoms & Chronic ulcer & $0-1(x 3)$ \\
& Need for special care & $0-1(x 3)$ \\
\hline \multirow{2}{*}{$\mathbf{0 - 1 2}$ points) } & Anxiety/insecurity & $0-3(x 3)$ \\
& Sadness/gloom & $0-3(x 3)$ \\
& Cognitive deficiency & $0-3(x 3)$ \\
& Behaviours that are hard to handle/manage & $0-3(x 3)$ \\
\hline \multirow{2}{*}{$\mathbf{0 - 9 8}$ points } & & \\
\hline
\end{tabular}

Regression analyses were then performed to find associations with these outcome categories in three steps:

1) The first regression analyses were performed to find significant associations between baseline health indicators and the SNAC outcome categories in table 4. The health indicators that demonstrated significant 
association to any of the outcome categories were included together with scores from the risk assessments, MMSE, and CDS.

2) The second regression analyses were performed to find significant associations between the five risk assessment extractions in table 3 and the SNAC outcome categories in table 4. These analyses also included the health indicators that demonstrated significant associations to any of the outcome categories in the first regression analyses (age, BMI, pulse pressure, and documented dementia).

3) The third regression analyses were then performed in order to explore more feasible ways to evaluate "frailty and need for care". Thus, these analyses were performed similar to the second ones but included only the item from each extraction that ranked the highest in each factor score (underlined in table 3).

\section{Specific methods for paper II}

\section{Study sample}

The study sample in paper II $(n=390)$ consisted of all SHADES subjects, but subjects with missing $\mathrm{Hb}$ values from visit 1 were excluded.

\section{Methods of investigation}

At baseline, descriptive characteristics for men and women were compared for subjects with and without anaemia. Assuming that the mean values were normally distributed, Student's T-test was used for continuous variables and the Chi-squared test for discrete variables. Mortality was compared for men and women with and without anaemia using Cox regression (proportional hazards analysis) with a follow-up time of up to around 7 years adjusting for age, increased BNP level and decreased eGFR. Subjects still alive on 1 January 2016 were considered as censored. The cohort with available 12-month follow-up values for $\mathrm{Hb}(\mathrm{n}=22 \mathrm{O})$ was divided into quartiles according to change in $\mathrm{Hb}$ value. The lowest quartile of $\mathrm{Hb}$ change (decline $>9 \mathrm{~g} / \mathrm{L}$ ) was compared with all other quartiles according to one year mortality and to the highest quartile (improvement $>6 \mathrm{~g} / \mathrm{L}$ ) in terms of baseline characteristics using Student's T-test for continuous variables and the Chi-squared test for discrete variables. 


\section{Specific methods for paper III}

\section{Study sample}

The study sample in paper III consisted of all SHADES subjects available for 6-month follow-up $(n=331)$.

\section{Methods of investigation}

The regularly used drugs registered in SHADES were classified in possible fall risk-increasing drug classes (antipsychotics, benzodiazepines, nonbenzodiazepine hypnotics, antidepressants, antihypertensives and vasodilators). The answer to the first question in DFRI regarding whether the person had fallen during the last year was used to identify falls that had occurred during the last 12 months. During the following 6 months, the study nurse registered all health care utilization, such as physician visits and hospitalization with associated main diagnoses. Falls with injuries requiring a physician visit or hospital care were considered serious falls, and were used in a prospective analysis. The sample's median age of 85 years was chosen to divide the study population into one younger group ( $<85$ years) and one older group ( $\geq 85$ years). The two age groups were analysed separately and compared according to the occurrence of serious falls, and the use of fall risk drugs.

A two-sided Pearson's Chi square test was used in a baseline analysis of associations between falls during the previous 12 months and the different drug classes. In the analysis of serious falls during the following 6 months, a two-sided Pearson's Chi square test or Fisher's exact test was used when comparing subjects using or not using the studied drug classes. A binary logistic regression analysis was used to calculate associations between drug use and serious falls in the two age groups, with the independent variables analysed separately. These calculations were also performed adjusted for the known fall risk factors: previous falls during the last 12 months, anaemia and cognitive impairment.

\section{Specific methods for paper IV}

\section{Study sample}

The study sample in paper IV $(\mathrm{n}=400)$ included all SHADES subjects, although subjects with missing MMSE at visit 1 and without a dementia diagnosis were excluded. 


\section{Methods of investigation}

Three groups of study subjects based on dementia diagnosis and cognitive function were compared. One group consisted of subjects with diagnosed dementia. Subjects without dementia diagnosis were grouped by MMSE result, where subjects with MMSE $\geq 24$ formed a control group, and subjects with MMSE <24 formed a cognitively impaired group named "possible dementia". Due to missing baseline MMSE, 28 study subjects without a dementia diagnosis were excluded. These subjects were not considered to differ from the study subjects in general according to answers from staff about their cognitive function.

Figure 4 The three compared groups in paper IV

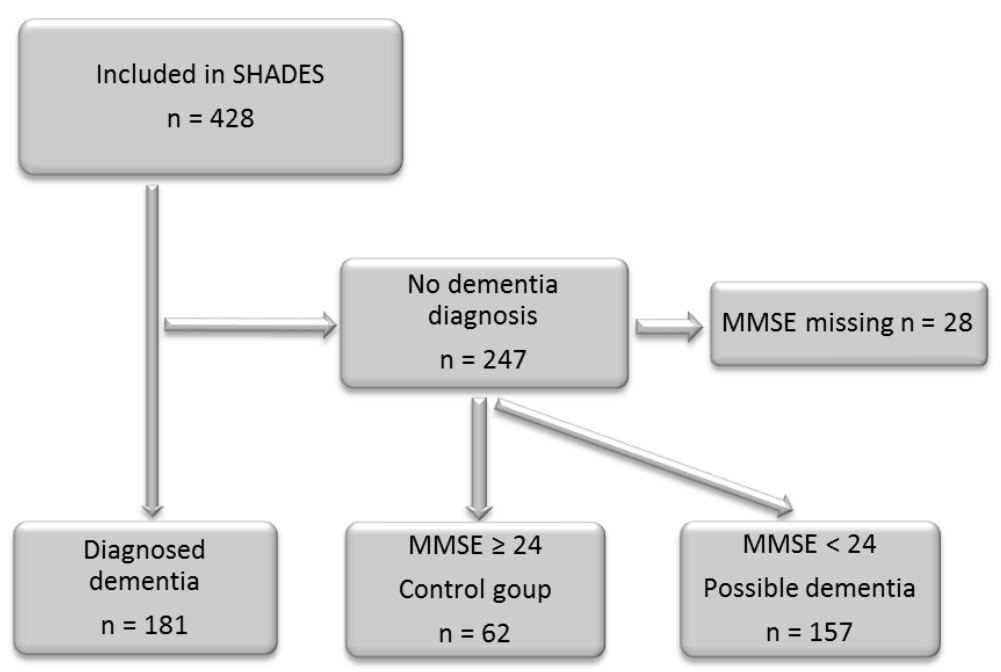

The three groups were compared according to baseline characteristics, including total number of regularly used drugs, number of psychotropic drugs, BMI, MMSE, pulse, systolic and diastolic blood pressure, and several blood analyses in order to compare the health status between the groups. For these comparisons, one-way ANOVA was used for continuous variables when the mean values were assumed to be normally distributed, Kruskal-Wallis test was used for continuous variables with considerable skewness, and the two-sided Pearson's chi-square test was used for discrete variables. A p-value of $<0.05$ was considered statistically significant.

The use of several drug classes and the occurrence of some general symptoms according to the different risk assessments and SNAC were also compared between the three groups. In these comparisons, the two-sided Pearson's chi-square test or Fischer's exact test was used. To avoid mass 
significance in these analyses, $\mathrm{p}$-values $<0.01$ were considered statistically significant and $\mathrm{p}$-values $<0.05$ but $\geq 0.01$ were considered non-significant tendencies. A Cox regression analysis with a survival plot of the three groups with adjustment for age and sex was also created for survival calculations.

\section{Statistical analyses}

All statistical analyses in papers I-IV were performed using SPSS (Statistical Package for the Social Sciences) versions 19-24 (SPSS, Inc. Chicago, IL). The statistical methods used are listed in Table 5 .

Table 5 Overview of study designs and data sources

\begin{tabular}{|c|c|c|c|}
\hline Paper & Design & Study subjects & Statistical methods \\
\hline I & Cross-sectional study & $\begin{array}{c}\mathrm{N}=315 \\
\text { (The first } 315 \text { study subjects included } \\
\text { in SHADES) }\end{array}$ & $\begin{array}{c}\text { Student's T-test } \\
\text { Chi-square test } \\
\text { Pearson correlation } \\
\text { Multiple linear regression } \\
\text { analysis } \\
\text { Explorative factor analysis with } \\
\text { Varimax rotation }\end{array}$ \\
\hline II & $\begin{array}{l}\text { Cross-sectional and } \\
\text { longitudinal cohort study }\end{array}$ & $\begin{array}{c}\mathrm{N}=390 \\
\text { (All SHADES subjects with } \mathrm{Hb} \text { value } \\
\text { available from visit } 1 \text { ) }\end{array}$ & $\begin{array}{l}\text { Student's T-test } \\
\text { Chi-square test } \\
\text { Cox regression analysis }\end{array}$ \\
\hline III & Longitudinal cohort study & $\begin{array}{l}\mathrm{N}=331 \\
\text { The subjects available for 6-month } \\
\text { follow-up in SHADES }\end{array}$ & $\begin{array}{c}\text { Student's T-test } \\
\text { Chi-square test } \\
\text { Binary logistic regression } \\
\text { analysis }\end{array}$ \\
\hline IV & $\begin{array}{l}\text { Cross-sectional and } \\
\text { longitudinal cohort study }\end{array}$ & $\begin{array}{l}\mathrm{N}=400 \\
\text { All SHADES subjects, but those with } \\
\text { missing MMSE without dementia } \\
\text { diagnosis were excluded }\end{array}$ & $\begin{array}{l}\text { One-way ANOVA } \\
\text { Chi-square test } \\
\text { Kruskal-Wallis test } \\
\text { Cox regression analysis }\end{array}$ \\
\hline
\end{tabular}

\section{Ethics approval and consent to participate}

The SHADES protocol was approved by the Regional Ethical Review Board, Linköping no. M150-07 (Papers I-IV) and 2016/67-32 (Papers IIIV). Written informed consent was obtained from all study subjects. For subjects with cognitive impairment who were unable to understand the information, the next of kin were consulted. 


\section{RESULTS}

\section{The SHADES cohort}

SHADES included a total of 428 nursing home residents, of whom 305 (71\%) were women and 123 were men. The mean age at inclusion was 85 years $( \pm 6.9)$ and the median age was 85 , with a range between 65 and 101 years. In some earlier studies on the SHADES cohort 429 subjects were included [129-134], but one subject was found to be 64 years old and excluded from later studies.

\section{Population characterisation and frailty}

Paper I described the first 315 study subjects included in SHADES. Their demographic data were the same as the complete SHADES population, with a mean age of 85 years and $71 \%$ were women. The women were significantly older than the men ( 86 vs 83 years). The study subjects had lived on average for over 2 years in the nursing home.

The study subjects had an average of three registered diagnoses. The most frequent diagnoses (prevalence $>10 \%$ ) were dementia (41\%), hypertension (27\%), stroke (23\%), diabetes (18\%), atrial fibrillation (16\%) and heart failure (14\%). The study subjects had an average of seven regularly used drugs. The most used drugs/drug groups (prevalence $\geq 20 \%$ ) were acetylsalicylic acid (54\%), paracetamol (44\%), antidepressants (43\%), diuretics $40 \%$ ), laxatives (40\%), beta blockers 31\%), hypnotics (30\%), vitamins (B12 or folic acid, 29\%) and sedatives (20\%). When analysing gender differences in diagnoses and drug use, the only significant difference was in the use of analgesics, where women used significantly more opioid analgesics and paracetamol compared to male subjects. The blood tests demonstrated a significantly lower mean level of $\mathrm{Hb}$ in women $(124 \mathrm{~g} / \mathrm{L}$ vs $129 \mathrm{~g} / \mathrm{L})$.

Among the risk assessments, MNA-SF showed that $60 \%$ were at risk of malnutrition ( $\leq 11$ points), MNS that $33 \%$ were at risk of developing pressure ulcers $\leq 20$ points) and DFRI showed that $93 \%$ had a risk of falling ( $\geq 3$ points). The CSDD scores were generally low (mean value 2.4 ) and only $4 \%$ had high scores $(\geq 10)$. Of those tested with MMSE, the mean score was 16.6 and $71 \%$ had scores $\leq 24$. 
The first regression analyses, performed in order to find associations between baseline health indicators and "frailty and need for care", included the variables documented diagnosis of dementia, stroke and heart failure together with age, pulse pressure, number of drugs and scores on MMSE, CSDD and the risk assessments. The score on MNS was the only one of those independent variables that demonstrated significant associations to all three outcome categories listed in table 4 and the total SNAC score. Psychological/cognitive symptoms were associated with age, pulse pressure, BMI, scores on MNS, documented dementia diagnosis and scores on MMSE. Somatic symptoms were only associated with age, scores on MNS and scores on DFRI. Functional problems or disabilities were associated with pulse pressure, BMI, documented dementia and scores on the MNA$\mathrm{SF}$, and scores on MNS.

The second regression analyses included the factor scores from the five extractions of the three risk assessments listed in table 3 together with the indicators that demonstrated significant associations to any of the outcome categories in the first regression analyses. The associations with "frailty and need for care" became clearer in these models (Table 6). The factor scores for physical ability, psychological/cognitive function and use of drugs were associated with all three outcome categories and the total SNAC score. The factor scores for sensory function were associated with three of the outcomes (all but somatic symptoms), and nutritional status was also associated with three outcomes (all but cognitive/psychological symptoms).

Table 6 Variables and factor scores associated with "frailty and need for care" and the three categories (standardized $\beta$ )

\begin{tabular}{|c|c|c|c|c|}
\hline & Somatic & $\begin{array}{c}\text { Cognitivel } \\
\text { psychological }\end{array}$ & Functional & Total \\
\hline $\mathbf{R}^{2}$ & 0.36 & 0.39 & 0,59 & 0.58 \\
\hline Age & $0.18^{\star *}$ & $-0.13^{*}$ & 0.06 & 0.09 \\
\hline Pulse pressure & 0.04 & $0.17^{* *}$ & 0.07 & $0.09^{*}$ \\
\hline BMI & 0.09 & $-0.28^{* *}$ & -0.03 & -0.10 \\
\hline Dementia diagnosis & 0.01 & 0.01 & -0.09 & -0.06 \\
\hline Physical ability & $-0.49^{\star \star}$ & $-0.13^{*}$ & $-0.69^{\star \star}$ & $-0.66^{\star *}$ \\
\hline Psychological/cognitive function & $-0.19^{* *}$ & $-0.46^{* *}$ & $-0.23^{* *}$ & $-0.30^{* *}$ \\
\hline Nutritional status & $0.13^{*}$ & -0.11 & $-0.13^{*}$ & $-0.11^{*}$ \\
\hline Sensory function & -0.02 & $0.23^{\star *}$ & $0.16^{* *}$ & $0.16^{\star *}$ \\
\hline Use of drugs & $0.18^{\star *}$ & $0.12^{*}$ & $0.17^{\star \star}$ & $0.20^{\star *}$ \\
\hline
\end{tabular}

${ }^{*} p<0.05,{ }^{* *} p<0.01$

The third regression analyses, performed in an attempt to simplify the measure of "frailty and need for care", included only the item with the highest score from each extraction (underlined in Table 3). As in the second regression analyses, pulse pressure, BMI and age were also included, 
but documented dementia was excluded since no association was found with any of the outcome variables in the second analyses. The results from the third regression analyses are presented in Table 7.

\begin{tabular}{|c|c|c|c|c|}
\hline & Somatic & $\begin{array}{c}\text { Cognitive/ } \\
\text { psychological }\end{array}$ & Functional & Total \\
\hline $\mathbf{R}^{2}$ & 0.43 & 0.33 & 0.53 & 0.55 \\
\hline Age & $0.15^{\star *}$ & $-0.20^{*}$ & 0.03 & 0.03 \\
\hline Pulse pressure & 0.05 & $0.20^{* *}$ & 0.07 & $0.11^{*}$ \\
\hline BMI & -0.08 & $-0.16^{* *}$ & -0.02 & -0.05 \\
\hline MNS motor ability & $-0.24^{\star \star}$ & -0.03 & $-0.57^{\star *}$ & $-0.67^{* *}$ \\
\hline MNS psychological status & $-0.19^{* *}$ & $-0.37^{* *}$ & $-0.09^{*}$ & $-0.41^{* *}$ \\
\hline MNA loss of weight & -0.07 & -0.01 & $-0.12^{\star *}$ & $-0.11^{*}$ \\
\hline MNS incontinence & $-0.43^{\star *}$ & $0.21^{* *}$ & $0.18^{* *}$ & $0.28^{* *}$ \\
\hline DFRI having fallen & $0.17^{\star *}$ & $0.15^{\star \star}$ & 0.06 & $0.12^{\star *}$ \\
\hline
\end{tabular}

${ }^{*} p<0.05,{ }^{* *} p<0.01$

\section{Anaemia}

In paper II on anaemia, study subjects with missing $\mathrm{Hb}$ values from visit 1 were excluded. Consequently, a total of 390 study subjects, 276 women (71\%) and 114 men (29\%), were included in the study cohort.

According to the WHO limits, $52 \%$ of the men and $32 \%$ of the women had anaemia (130 and $120 \mathrm{~g} / \mathrm{l}$ respectively). However, when the same anaemia limit were used for men as for women $(120 \mathrm{~g} / \mathrm{L})$, the anaemia occurrence was considerably lower among men (27\%), with no significant difference from women $(\mathrm{p}=0.325)$. Among women, subjects with anaemia were significantly older than subjects without anaemia ( 87 vs 85 years, $p=0.037$ ). Among men, there was the same tendency but the age difference was not significant ( 84 vs 82 years, $p=0.064$ ). Otherwise, there were no significant differences in weight, height, BMI, time for physical activity or time for social activity between women with and without anaemia. Among men, the only difference was that subjects with anaemia were less physically active. There were no significant differences in number of regularly used drugs between men and women or subjects with and without anaemia, nor did subjects with anaemia use drugs that could increase the risk of bleeding to a greater extent than subjects without anaemia.

Two-year mortality was significantly higher (61\%) for men with anaemia than for men without anaemia $(29 \%, p=0.001)$. Among women, there was no statistical difference in two-year mortality for subjects with or without anaemia ( $49 \%$ vs $43 \%, p=0.340$ ). The difference in mortality 
during the total follow-up time (up to about 7 years) is presented as survival curves for men and women with and without anaemia in figure 5 .

\section{Figure 5 Survival curves for women and men with and without anaemia}

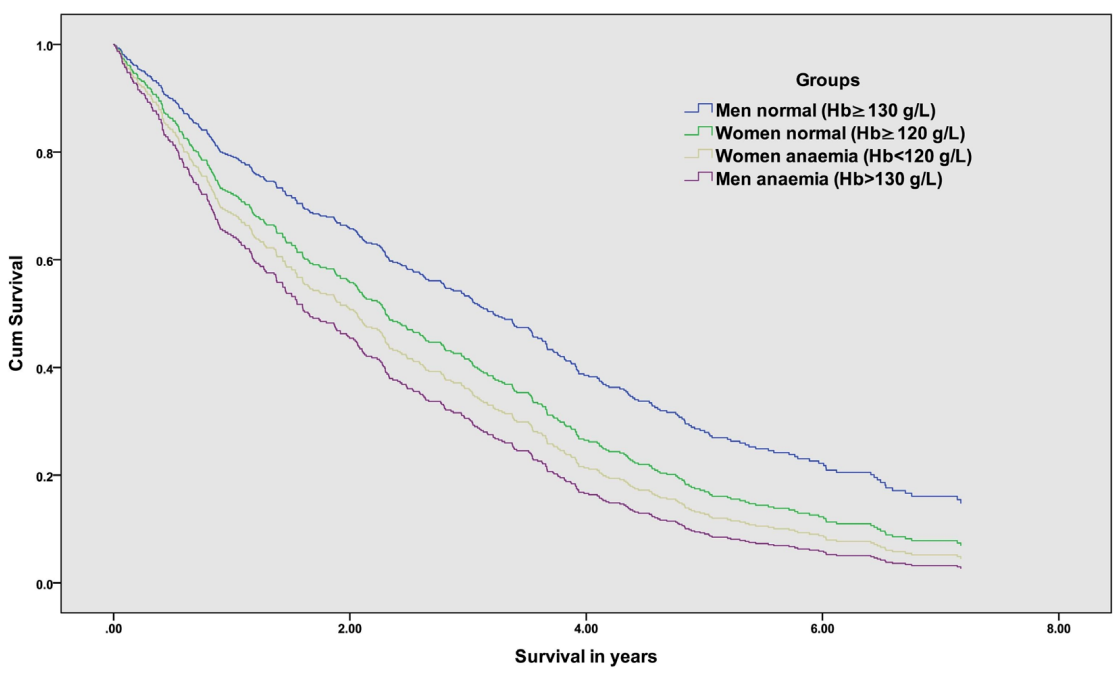

During this follow-up time, the difference in mortality was not significant between subjects with or without anaemia when all subjects were analysed together, with or without adjustment for age, increased BNP and decreased estimated glomerular filtration rate (eGFR). However, when stratified for sex, the difference in mortality between male subjects with or without anaemia during the follow-up period was significant even when adjusting for age, increased BNP and decreased eGFR (Hazard Ratio 1.58). Among female subjects, there was no significant correlation between anaemia and mortality but a correlation between increased BNP and mortality.

When correlations between anaemia and some potential causes of anaemia were investigated, there were differences between men and women. Among men there were correlations between anaemia and elevated BNP $(>100 \mathrm{ng} / \mathrm{L})$ and with severely reduced eGFR $(<30 \mathrm{ml} / \mathrm{min})$. These correlations were not seen among women. Among women we found correlations between anaemia and several markers of inflammation, such as decreased transthyretin $(<0.23 \mathrm{~g} / \mathrm{L})$, increased ferritin $(>204 \mu \mathrm{g} / \mathrm{L})$ and increased CRP ( $\geq 10 \mathrm{mg} / \mathrm{L})$. Among men with anaemia, there was a correlation with increased CRP, but not with increased ferritin $(>275 \mu \mathrm{g} / \mathrm{L})$ or transthyretin $(<0.23 \mathrm{~g} / \mathrm{L})$. 
Finally, prospective data after 12 months were used to compare the quartiles in $\mathrm{Hb}$ change. In the lowest quartile (decline more than $9 \mathrm{~g} / \mathrm{L}$ ), there was significantly higher mortality during the subsequent 12 months (36\%) compared to each of the other quartiles (18\% in all separate quartiles). The lowest quartile in $\mathrm{Hb}$ change (decline more than $9 \mathrm{~g} / \mathrm{L}$ ) had higher $\mathrm{Hb}$ at baseline compared with the highest quartile in $\mathrm{Hb}$ change in both men (134 vs $113 \mathrm{~g} / \mathrm{L}, \mathrm{p}$ <0.001) and women (128 vs $120 \mathrm{~g} / \mathrm{L}, \mathrm{p}=0.007$ ). There were no other significant differences including age, sex, number of drugs, BMI, eGFR, BNP, MNA-SF score or MMSE score when the lowest and highest quartiles in $\mathrm{Hb}$ change were compared.

\section{Falls and drugs}

Paper III included the 331 SHADES subjects available for 6-month followup. Of those, 234 were women (71\%) and 97 were men (29\%). Median age at inclusion was 85 years (range 65-101 years). Dividing the sample at median age created one younger group (164 subjects, age 65-84 years) and one older group ( 167 subjects, age 85 years or above).

On average, the study population regularly used $6.9 \pm 3.1(0-14)$ drugs. A dementia diagnosis was documented in 143 subjects (43\%), but among the subjects tested with MMSE, 81\% had cognitive impairment (MMSE $<24)$. A large majority had an increased fall risk as measured by DFRI $\geq 3$ (93\%). The use of drugs differed somewhat between the age groups, with significantly less polypharmacy and also significantly less use of antidepressants and antipsychotics in the older age group. 80 subjects regularly used non-benzodiazepine hypnotics (67 zopiclone, 13 zolpidem).

For $62 \%$, there was at least one reported fall during the previous year (answer "yes" to DFRI question no. 1). There was a higher occurrence of reported falls during the previous year in the subjects with regular use of non-benzodiazepine hypnotics ( $\mathrm{p}=0.005)$, but there were no significant differences in reported falls for other studied drug classes. Over the next 6 months, 24 (7.3\%) subjects experienced serious falls, 12 in the younger group and 12 in the older group. Those with falls reported from the previous year in DFRI had a non-significant tendency towards a higher risk of serious falls in the following 6 months $(\mathrm{p}=0.094)$. For the entire sample, the occurrence of serious falls in the following 6 months did not differ significantly when comparing groups of subjects using or not using drugs from different drug classes. In the older age group, however, there was a significant association between serious falls and regular use of nonbenzodiazepine hypnotics ( $\mathrm{p}=0.017$, odds ratio 4.311 ), but no significant associ- 
ation between serious falls and regular use of the other studied drug classes. These results did not change when adjusting for the included fall risk factors previous falls, anaemia or cognitive impairment. Among the study subjects treated with non-benzodiazepine hypnotics at baseline, $91 \%$ were still on this treatment after 6 months.

Observations in the older group (aged $\geq 85$ ) were that seven out of 12 subjects with serious falls were on non-benzodiazepine hypnotics regularly. Five out of six subjects with serious falls aged $>90$ years were on nonbenzodiazepine hypnotics regularly. Four out of six subjects in the whole sample for whom a hip fracture had occurred were on non-benzodiazepine hypnotics regularly. All subjects $\geq 90$ for whom a hip fracture had occurred were on non-benzodiazepine hypnotics regularly (ages 90, 92 and 94).

\section{Cognitive impairment}

Paper IV included 400 study subjects with a mean age of 85 years (range 65 to 101 years), of whom 234 (71\%) were women. Three groups of subjects were compared: 181 subjects with a dementia diagnosis, 157 subjects without diagnosed dementia but MMSE $<24$ suggesting possible dementia, and 62 subjects without diagnosed dementia and MMSE $\geq 24$ who formed a control group.

In baseline characteristics the three compared groups differed significantly in age, weight, height and number of medications. The possible dementia group was significantly older than the diagnosed dementia group (86 vs 84 years, $p=0.031$ ), but otherwise these two groups did not differ significantly in any other general characteristics. Blood analyses showed significantly higher BNP levels in the possible dementia group compared to the diagnosed dementia group (mean value 226 vs $155 \mathrm{ng} / \mathrm{L}, \mathrm{p}=0.020$ ). When we analysed the proportion of subjects with high BNP levels $(\geq 100$ $\mathrm{ng} / \mathrm{L}$ ) there was also a significantly higher proportion of high values in the group with possible dementia compared to the group with diagnosed dementia ( $59 \%$ vs $43 \%, p=0.019$ ), a difference that remained when subjects with known heart failure were excluded ( $53 \%$ vs $37 \%, \mathrm{p}=0.040$ ). The proportion of subjects on substitution with cobalamin and folate differed significantly between the three groups. However, when the subjects who were on substitution were excluded there were no significant differences in mean serum cobalamin or folate levels or prevalence of low values between the three groups. 
Polypharmacy was more common in the control group than in the other two groups. The possible dementia group was rarely treated with the antidementia drugs acetylcholinesterase inhibitors and memantine (2.5\%). More subjects in the control group were treated with hypnosedatives than in the diagnosed dementia group ( $43.5 \%$ vs $25.4 \%$ ). There were more subjects on therapy with diuretics (54.1\% vs $37.6 \%)$ and less substitution with cobalamin ( $28.7 \%$ vs $44.2 \%$ ) and folate (34.8\% vs $12.7 \%$ ) in the possible dementia group compared to the diagnosed dementia group.

The risks of malnutrition and pressure ulcers were assessed to be similar in the possible dementia group and the diagnosed dementia group, but significantly higher in the possible dementia group compared to the control group (for MNA-SF 60.9\% vs 33.9, for MNS $49.7 \%$ vs $22.6 \%$ ).

Figure 5 shows survival curves for the three groups adjusted for age and sex. The differences in mortality between the groups were not significant.

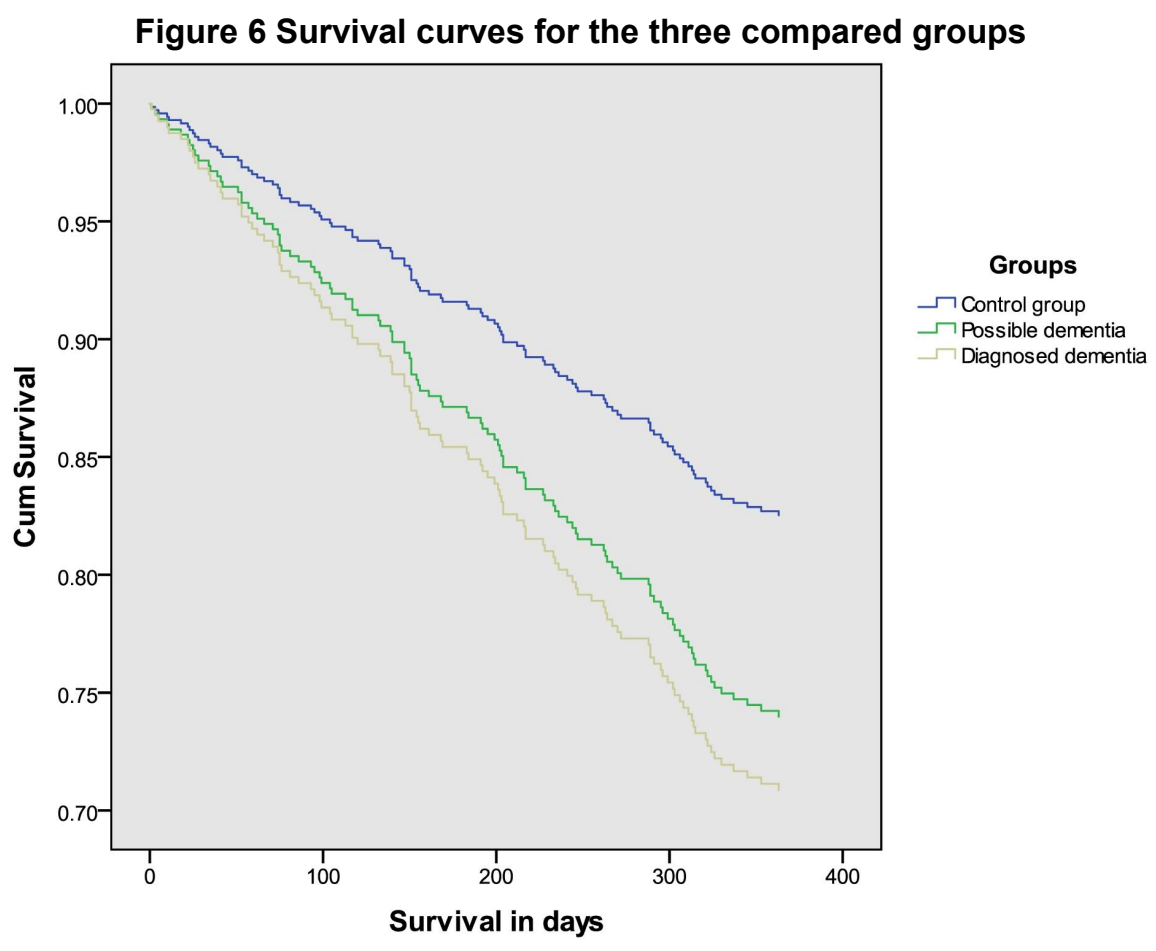




\section{DISCUSSION}

This thesis explores some geriatric aspects of frail older nursing home residents using the SHADES population. Paper I describes some overall aspects of the population and of frailty. Papers III-IV focus on anaemia, associations between falls and drugs, and cognitive impairment respectively. In addition to the papers on which this thesis is based, there are several other articles published on various aspects of the SHADES population [129-139].

\section{Population characterisation and frailty}

Paper I confirmed that people living in Swedish nursing homes are old (mean age 85 years), with comorbidity (mean of three diagnoses) and polypharmacy (mean of seven regularly used drugs). Dementia was the most prevalent diagnosis, with an occurrence of more than two out of five, however MMSE indicated significantly higher prevalence of cognitive impairment. The most frequent diagnoses and the most frequently used drugs were the ones to expect in this population.

The performed risk assessments revealed that more than half (60\%) of the sample were at risk of malnutrition, one third were at risk of developing pressure ulcers, and nearly all (93\%) had a risk of falling. This indicates a fragile population, but also raises questions about the usefulness of the fall risk assessment DFRI in particular in nursing home populations.

A wider concept, "frailty and need for care", was used in paper I as a definition of frailty. In this definition the items from SNAC [127] were used. As described, three different subscores were formed (Table 4) and these, together with the total SNAC score, were used with the intention to describe different types of frailty. These three categories, motivated by previous studies, were named "functional problems or disabilities", "somatic symptoms" and "psychological or cognitive symptoms". "Functional problems or disabilities" were motivated as disability may contribute to frailty and vice versa [140]. "Somatic symptoms" due to a combination of declines in physiological stores in older people, diseases and use of drugs, may lead to a vulnerable situation definable as frailty [141]. "Psychological or cognitive symptoms" were motivated as measures of cognition and mood were included in descriptions of frailty [37]. In conclusion, all items 
used to define "frailty and need for care" were originally used to assess the need for care and services for older individuals, an important reason for defining and measuring frailty. The used model has most similarities with the deficit accumulation model launched by Rockwood [36], but also includes a multidimensional perspective similar to the later suggested model by Gobbens [38, 39], but without the social perspective.

The number of drugs was not associated with the definition of "frailty and need for care" in the first regression analyses. There is a conflict between increasing drug use due to comorbidity and the problem of polypharmacy as comorbidity and vulnerability increase with age. Recent European expert consensus has highlighted the need to re-evaluate drug therapies towards the end of life, for example in terminally ill dementia, [142] and more similar recommendations are likely to follow in the immediate future.

The designation of the extraction "use of drugs", used in the second regression analyses, is somewhat misleading as it included several drugrelated items but also the DFRI item "having fallen". This extraction factor score had an impact on all outcome variables in the second regression. However, the third regression analysis demonstrated that this impact was in fact due the single DFRI item "having fallen". In conclusion, the number and use of certain drugs had less importance in relation to "frailty and need for care".

The factor analysis performed with the items from the three risk assessments (MNA-SF, MNS and DFRI) demonstrated that these risk assessments used in elderly care today overlap each other, catching up with similar problems. Consequently, the risks of malnutrition, pressure ulcers and falls are highly interacted. Medical treatment, care, services and prevention in those older individuals should be performed individually based on a holistic view, and this in turn will lead to a decreased risk of severe conditions. The different risk scales constitute an established tool for the prevention of adverse events in Swedish elderly care, but are not needed to provide individual-based care for nursing home residents.

The conclusion from the third performed regression analyses, which aimed to explore more feasible ways to evaluate "frailty and need for care", was that age, pulse pressure, BMI, and the five individual items MNS motor ability, MNS psychological status, MNS incontinence, MNA loss of weight and DFRI having fallen explained most of the variation in "frailty and need for care" $\left(\mathrm{R}^{2}=0,55\right)$. These eight items also had a signifi- 
cant impact on the three outcome categories. However, there remains a considerable variation in "frailty and need for care" and the outcome categories that is not explained by these eight variables.

As previously stated, there is still no established definition or standardized assessment instrument for frailty [40,143]. The early instrument Physical Frailty Phenotype (PFP) [35], is however the most commonly used one. Retrospectively, it is regrettable that SHADES did not collect sufficient data to estimate frailty according to this instrument since that would have provided valuable analysis possibilities in combination with other collected data. Complementary measurement of grip strength and walking speed may have been sufficient as performed assessments included items for estimating the other components in the instrument.

\section{Further comments on some results in paper I}

The overall relatively low scores for CSDD indicate a low prevalence of depression. However, there are some remarks to make that may influence the interpretation of the results. First, CSDD, as developed to assess signs and symptoms of depression in dementia, is intended to use a comprehensive interviewing approach that derives information from both the patient and an informant [123]. In SHADES, however, CSDD was completed solely with the assistance of staff members. The cut-off limit used in paper I is $\geq 10$ points, as suggested in a later manual by the original author. This cut-off limit is however poorly motivated overall and a later used limit indicating depression is $\geq 8$ points [144]. Consequently, that limit is used in a paper based on the SHADES cohort focusing on depression treatment [133].

A great majority of the subjects in paper I tested with MMSE had low scores, possibly indicating cognitive dysfunction. However, there are two remarks to be noted. First, not all the subjects were tested with MMSE. The failure frequency, not reported in the paper, was $18 \%$ ( 57 subjects) for MMSE. Among the reasons for failure were blindness, severely impaired hearing and aphasia, as well as severe cognitive dysfunction or refusal. Second, it should be noted that the limit used in paper I is $\leq 24$ and not $<24$ as used in papers III-IV, which is most widely used and traditionally recommended [115]. Taken together, these remarks suggest that cognitive impairment is more frequent in the studied population than indicated in paper I. Further aspects of cognitive function in the SHADES population are discussed separately in paper IV. 
The noted gender difference, with blood tests demonstrating a significantly lower mean level of $\mathrm{Hb}$ in women (124 g/L vs $129 \mathrm{~g} / \mathrm{L}$ ), is further discussed in paper II on anaemia.

\section{Anaemia}

About one third of the women and half of the men in SHADES had anaemia according to the WHO limits [46]. The anaemia prevalence in earlier nursing home studies using these limits is somewhat divergent, probably due to diversity in nursing home populations, but the overall prevalence is estimated to be at a similar level, however with a higher prevalence in women in some studies compared to SHADES [57-59, 145-148].

A main finding in paper II was a gender difference in the association between anaemia and mortality, with a higher mortality rate among men with anaemia compared to men without anaemia, both in two year mortality and in Cox regression analyses up to 7 years. The association was still significant among men when adjusting for the covariates age, increased BNP and decreased eGFR. There was not the same higher mortality rate among women with anaemia compared to women without anaemia. No other studies were found that had been performed in a nursing home population and that described gender differences regarding anaemia as a risk factor for mortality. One study described a slightly higher mortality risk increase in community-living men with anaemia than in women [54]. Interestingly, a smaller Japanese case-control study performed in 1990-1996 on anaemia in nursing home subjects showed similar differences in survival curves during a follow-up period of 5 years. However, that study used a lower anaemia limit ( $110 \mathrm{~g} / \mathrm{L})$ for both genders, few men were included and the gender differences were not described [149].

Increased BNP and decreased eGFR were more common among men with anaemia compared to men without anaemia in SHADES. This may indicate that men in nursing homes with anaemia have more severe underlying causes of anaemia than women. This is consistent with previous conclusions that the higher frequency of anaemia in men can be explained by a higher prevalence of underlying diseases [54]. However, a higher mortality rate remained after adjustment for these variables.

Another finding was that $\mathrm{Hb}$ decline during the last year was correlated with doubled one-year mortality. Interestingly, there was a significant difference in baseline $\mathrm{Hb}$ values when the worst and best outcome quartiles 
on $\mathrm{Hb}$ change were compared, with higher baseline $\mathrm{Hb}$ values in the quartile with the greatest decline. A previous study in a somewhat younger community-living population of older people (mean age 72.1 years) [150] suggests that it is difficult to predict declining $\mathrm{Hb}$ based on the current $\mathrm{Hb}$ level. According to the present results, this seems to be applicable even in an older and frail nursing home population.

As previously noted, the WHO limits are under considerable scientific debate, especially for use in older populations. However, a previous community-based study concludes that further clinical investigation is recommended if an older person's Hb concentration is below the WHO normal values, even if the person is without apparent clinical disease [54]. The results in paper II support the applicability of this, even in a nursing home population. Furthermore, gender differences in anaemia limits may be relevant even at higher ages because anaemia in men, defined from a higher limit, seems to be prognostically unfavourable. Overall, there is some confusion about which $\mathrm{Hb}$ limits to use. The WHO limits are used in several Swedish recommendations for use in adults in general. However, there is also a variation between local laboratories, and lower normal limits of 115-117 g/L for women and higher limits of 134-135 g/L for men are sometimes specified.

Despite risks with anaemia regarding for example mortality and falls [66], there may be a risk that low $\mathrm{Hb}$ values or $\mathrm{Hb}$ decline is overlooked and not further investigated in a nursing home population. The symptoms of anaemia are vague in older patients and the onset of symptoms is usually insidious [50]. Other contributing factors may be complex comorbidity, a belief that the investigation results do not change treatment options and a lack of time.

In conclusion, a low $\mathrm{Hb}$ value in an elderly nursing home resident shall be considered a marker of disease and a warning signal for death, especially among men. Furthermore, a higher $\mathrm{Hb}$ value is no protection against an $\mathrm{Hb}$ decline, which also is a separate warning signal and correlated with higher mortality. Consequently, the results support regular control of $\mathrm{Hb}$ values in a nursing home population, and comparison with previous values.

There is a need for more knowledge about the causes of anaemia in a nursing home population. A considerable proportion of about one third of anaemia cases in older populations are classified as of unknown origin $[45,50]$. A more specific diagnosis may have implications for treatment. 
Among the possible suggested therapeutic options for the future are erythropoietin analogues [57, 145] or androgens [52].

\section{Falls and drugs}

The main finding in paper III was an association between falls and regular use of non-benzodiazepine hypnotics. Regular use of these drugs was associated with falls during the previous year. Furthermore, when the study group was divided at the median age of 85 years into one younger and one older group, non-benzodiazepine hypnotics were also associated with serious falls during the next 6 months in the older group. There was no association between reported falls during the previous year or serious falls in the following 6 months and the other investigated drug classes.

These results are important since non-benzodiazepine hypnotics, being a relatively new hypnotic drug class, have been considered safer [151], welltolerated by older people [88] and therefore suitable in this population. Consequently, these drugs are widely recommended as first line pharmacological insomnia therapy for older people [73, 89, 90], and zopiclone is also more commonly used in institutionalized compared to communitydwelling older people in Sweden [91].

The results are also consistent with the previous US nursing home study that showed an elevated hip fracture risk in nursing home residents using a non-benzodiazepine hypnotic [92]. However, compared to SHADES, that population was younger ( $\geq 50$ years, mean age 81 ) and US prescription options and traditions within the group of non-benzodiazepine hypnotics differ from those in Europe.

The use of psychotropic drugs in SHADES was at the same level as in an earlier report from Swedish nursing homes [91], but lower than in an earlier Swedish study on specialized care units for persons with dementia [152]. However, in SHADES, there were considerable differences in psychotropic drug use between the older and younger groups. The older group were on a polypharmacy regimen ( $\geq 10$ drugs) to a significantly lower extent, they used significantly less antidepressants and antipsychotics, and there was a non-significant trend towards a lower use of benzodiazepines. Regarding non-benzodiazepine hypnotics, the tendency was the opposite, however, not significant. A possible explanation for these differences in drug use could be presence of more physical frailty and less psychiatric symptoms in the oldest group. However, polypharmacy and certain types of psychotropic drug use are established risk treatments for 
older people, a fact that had been highlighted in previous guidelines [73]. Consequently, a deliberate adaptation of the medication to an older frail group may be another reason why this study could not find any association between the use of other studied possible fall risk-increasing drug classes and falls.

More safety concerns on non-benzodiazepine hypnotics related to effects on balance and fracture risk in older people have been raised during the last few years [153, 154]. Negative effects from non-benzodiazepine hypnotics on postural stability 4-8 hours after low-dose zopiclone or zolpidem intake have been shown even in healthy persons aged 64-79 years $[155,156]$. Consequently, non-benzodiazepine hypnotics have now been mentioned as fall risk drugs in the recent versions of Beers Criteria $[78,79]$ and STOPP Criteria [81] published after the SHADES data were collected.

Some previous studies on non-benzodiazepine hypnotics and fracture risk in older people have found an increased fall risk associated with shortterm use or during the initial period on a new drug $[92,157,158]$. The results in paper III apply to regular drug use over a longer period, which is not unusual in nursing home residents.

As nursing home residents are a frail group with a very high fall risk, there is a need for high attention to use of drugs that further increase fall risk. As hypnotics and sedatives in general are fall risk-increasing, there is a need for more awareness and education in the area of non-pharmacological approaches for insomnia. Nursing homes need to establish a culture that does not use drugs as a first line action. Earlier studies have shown considerable variation in the use of various psychotropic drugs between nursing homes with comparable populations [159-161]. These studies indicate that drug use in nursing homes is influenced by differences in individual prescription practice between doctors or different prescription traditions between nursing homes. Furthermore, there is a need to evaluate potentially less sedative pharmacological treatments such as melatonin in this population.

The fact that almost all study subjects (93\%) had an increased fall risk according to DFRI raises questions about the utility of this instrument in nursing homes, and indicates a need for better instruments for the identification of those with the highest fall risk. The fact that the majority (62\%) had fallen during the last year stresses a need for better and generally per- 
formed fall prevention actions, one of them being regular medication overviews.

In general, there is a lack of studies on fall risk in very old people. An exceedingly high fall risk in those aged over 90 without considering pharmacological treatment is reported [162]. No studies were found that analysed the use of non-benzodiazepine hypnotics or the effects on stability among the oldest old ( $\geq 85$ years). In light of this, the described incident serious falls and hip fractures among the oldest non-benzodiazepine users in SHADES further highlight this area for more future research.

\section{Cognitive impairment}

Cognitive impairment (MMSE <24) was found in $72 \%$ of the subjects without dementia assessed with MMSE. As MMSE was missing for 28 subjects, a plausible estimation is that 177 subjects in the original sample of 428 may have undiagnosed dementia compared to 181 with a dementia diagnosis. Consequently, up to $84 \%$ in the total sample had a cognitive impairment, which is in line with previous studies with a similar approach [110-112, 163]. However, only half of the subjects in SHADES with cognitive impairment had a known dementia diagnosis.

Furthermore, there were differences of clinical importance between the cognitively impaired group with possible dementia (MMSE <24) and the diagnosed dementia group. Higher occurrence of elevated BNP levels in the possible dementia group may indicate under-treated heart failure, which is previously known to be associated with cognitive impairment [164] and dementia [165]. Published data from SHADES have shown a tendency towards higher cognitive function in subjects with established heart failure diagnosis compared to subjects without diagnosed heart failure [130]. A recent Norwegian nursing home study [163], suggests that subjects with cognitive impairment generally have less attention paid to their physical symptoms which may lead to undiagnosed physical disease. In SHADES, there were some differences in cardiovascular drug treatment between the groups that may reflect undiagnosed or undertreated heart failure. More diuretic use in the possible dementia group than in the dementia group may reflect symptomatic treatment of undiagnosed heart failure. The control group, without cognitive impairment and possibly with more somatic illness, uses the same amount of diuretics but also has a tendency to use more beta blockers. 
BNP levels can be influenced by renal function and age [166]. However, age differences in the present study, though significant, were not considered to influence BNP differences more than marginally, and there were no differences between the groups in renal function as measured by GFR.

The older age of the possible dementia group indicate that age might affect the amount of attention paid to cognitive impairment. Few subjects in the possible dementia group were on treatment with anti-dementia drugs, which presumably confirms that no dementia investigation was performed. This is also supported by the fact that substitution with cobalamin and folate were more common in the diagnosed dementia group, since there is an established practice of starting substitution with these vitamins at serum levels below or in the lower normal area in connection with performing a dementia investigation. However, there were no differences in serum cobalamin or folate levels among individuals without substitution. Overall, the possible dementia group showed several similarities with the dementia group such as high risk of malnutrition and pressure ulcers and a similar mortality rate.

SHADES used MMSE [114] to assess cognitive function. MMSE is widely used as a screening instrument for cognitive impairment. MMSE scores range from o to 30, with a score below 24 generally used to raise a suspicion of cognitive impairment [115]. Even though the 24 cut-off level has been challenged [116], it can be regarded as a conservative cut-off level with few false positive cases. However, MMSE is a screening test. A dementia diagnosis shall be based on cognitive deficits that cause impairment in social or occupational function and not only a cognitive test as suggested by the Diagnostic and Statistical Manual of Mental disorders (DSM) 4 criteria, applicable at the time of SHADES data collection [167]. Later published DSM 5 criteria [168] define the new term "major neurocognitive disorder", replacing dementia, as a significant cognitive decline in one or more cognitive domains that interferes with independence in ADL. In nursing homes, evaluation of cognitive and ADL function may be a challenge, and which instruments to use in nursing home populations can be discussed.

In conclusion, un-noted cognitive impairment in nursing home residents is common and may indicate other potentially treatable conditions such as heart failure. Undiagnosed cognitive impairment however also exhibits several similarities with diagnosed dementia such as a high risk of malnutrition and pressure ulcers and a similar mortality rate. In clinical prac- 
tice, these findings highlight the need to pay increased attention to signs of cognitive impairment in nursing home residents.

In addition, the high prevalence of cognitive impairment among nursing home residents places great demands on adapting the nursing home environments and educating staff members. There is a need for the staff to be aware of signs of cognitive impairment, but also to understand the consequences of cognitive impairment and to be able to interact with and understand the needs of the cognitively impaired resident.

\section{Methodological considerations}

\section{SHADES generally}

SHADES included a population that was old (mean age of 85) and frail. This is a patient cohort where studies are limited and a group that is often excluded in studies. Overall, 428 subjects were included, which constitutes a substantial cohort in this type of study. However, the total sample is somewhat limited to performing subgroup analyses, and these should therefore generally be interpreted cautiously.

A possible general limitation of SHADES is that nursing homes showing interest in participation were chosen for the study as SHADES was dependent on stable conditions to facilitate repeated measurements for up to 3 years. Generally, the research group considered the included nursing homes to be representative of Sweden, and the fact that they are from three different areas increases the probability that they are representative. Furthermore, the number of drugs was at the same level as in a contemporary Swedish nationwide study on drug use in nursing homes [91], thus supporting representability. The study is unique in collecting longitudinal data; however a high mortality rate in this population is to be considered.

Data were collected in the period 2008-2011, and traditions in drug use and the health status of older people living in nursing homes may have changed in recent years. However, during the last few years there has been less reduction in nursing home beds in Sweden than previously, and there has also been a period of fewer demographic changes compared to previous years $[2,26]$. Therefore, the population in nursing homes in general is believed to be similar and the results thus considered relevant and still applicable in nursing homes. The observational design of SHADES means that the study may generate hypotheses, but precludes any definite conclusions about causality. 
As described, all included subjects in SHADES are nursing home residents and the results therefore cannot be extrapolated to older people in general. The compliance to prescribed drugs is generally believed to be more reliable in nursing home residents compared to older people in independent living.

\section{Population characterisation and frailty}

In paper I some of the variables in MNS, MNA-SF, and DFRI are similar to the SNAC items used for defining "frailty and need for care". Consequently, the cause and effect could be questioned. However, the risk assessments (MNS, MNA-SF, DFRI) are created to determine the risk of different conditions and the outcome variables (SNAC) are created to analyse the need for care and services. In this study, it was not possible to analyse whether the risk assessments predicted what they were supposed to (pressure ulcers, malnutrition and falls). Too few of the sample had pressure ulcers. There is no gold standard to measure malnutrition, but using the results from the MNA or MNA-SF is a relatively common way together with blood samples and BMI. As BMI is included in MNA-SF and occurred falls are included in DFRI the results would have been biased. These facts should be considered when interpreting the results. Reference values and failures need to be considered regarding MMSE and CSDD values as commented on in the discussion section.

\section{Anaemia}

Paper II may be biased by the fact that palliative patients were excluded at inclusion. There may be gender differences, not analysed in SHADES, regarding the underlying reason for moving into a nursing home. Since women have a longer life expectancy than men, and therefore often survive their spouse, severe somatic disease may theoretically be a more common reason for nursing home care among men, while psychosocial factors such as loneliness and the need for stimulation may matter more to women. The lower anaemia rate among the women in this study compared to other nursing home studies may support this hypothesis, and may influence the results.

\section{Falls and drugs}

Paper III is important because few fall risk studies have been performed in nursing homes that include non-benzodiazepine hypnotics, especially in Europe, and since these substances are considered comparably "less harmful" for older people. Furthermore, fall studies in the oldest populations are scarce [162]. However, the small overall number of serious falls is an important limitation. Consequently, differences in fall risk between drug users and non-users should be interpreted cautiously and need to be 
confirmed in larger studies. A possibility of increased awareness about inappropriate drug use in the included nursing homes cannot be excluded. The baseline registration of occurred falls during the last 12 months is based on the answers from nursing home staff to a question about whether or not the person had fallen. This constitutes a possible source of error, since the collection of formal fall reports would represent more robust data, but unfortunately these reports are not available. Dose-response relationships were not examined due to the small overall sample size, and data about drugs taken as needed were not registered. Finally, the start dates for different drugs were not registered, nor were we able to confirm that a subject was still on the same medication when a serious fall occurred up to 6 months later. However, there were few changes in the treatment with non-benzodiazepine hypnotics over the study period of 6 months.

\section{Cognitive impairment}

Studies on cognitive impairment or dementia are generally difficult to compare because there are differences in diagnostic tools and underlying populations, as previous reviews have pointed out [103, 106]. A strength in paper IV is that cognitive assessment in SHADES was carried out through a personal assessment with MMSE. However, MMSE is a screening instrument and the study lack a proper diagnostic evaluation of the group with cognitive impairment. Notably, the total prevalence of cognitive decline in this study is in line with the dementia prevalence at admission to nursing home in a recent Norwegian study [110].

\section{Clinical considerations}

\section{About the studied topics}

The studied topics in this thesis (frailty, anaemia, falls and cognitive impairment) are all frequently prevalent in the SHADES population. One thing that frailty, anaemia and cognitive impairment have in common is that definitions or limits are discussable and not very distinct. Frailty and cognitive impairment in earlier stages may be hard to distinguish from normal ageing and may be considered as part of normal ageing by the public. The lack of clear definitions makes results hard to evaluate. Furthermore the studied topics overlap and influence each other. This can be exemplified by frailty, cognitive dysfunction and anaemia all having been shown to increase the risk of falls. This complexity must be considered and means that the results should generally be interpreted cautiously. 
Another example of how the topics overlap each other is the suggested concept of cognitive frailty, a term initially suggested and described a little over a decade ago [169] and mentioned in an increasing number of research articles during the last few years. This concept ties together two "giants of geriatrics", and may be a concept of interest for the future, especially in the studied population. A complex relationship between frailty and Alzheimer's dementia has very recently been described [170]. This work suggests that the degree of frailty may modify the association between cerebral Alzheimer's disease pathology and symptoms of Alzheimer's dementia. If frailty is to some extent a treatable or at least preventable condition, this is of great importance.

\section{Medical care in nursing homes}

Nursing homes are an important part of the Health and Welfare System in Sweden as in other countries. The long-term care in nursing homes is considered part of the social welfare system, and the responsibility lies with the local municipalities. However, the morbidity and frailty of nursing home residents described in this thesis require significant elements of medical supervision.

The physicians regularly visiting the nursing homes in Sweden are employed within the primary care system and act as consultants. These physicians have some time set aside to support the nursing home with regularly visits. Studies in different countries have found that physicians responsible for nursing home residents feel influenced by a lack of time [171] and by workload [172], and sometimes find their work in nursing homes difficult and unappealing [173]. In contrast, for the interested physician, the regular visits to nursing homes is also a part of their work that offers variety and is less time controlled than their ordinary work. These physicians often find their work in nursing homes enjoyable, important and meaningful [174].

Working with very old nursing home residents with considerable comorbidity includes a balance between the demands from the nursing home staff or the patient's relatives for medications and the patient's actual need for care, a balance that requires a holistic view and experience to manage. More guidelines on how to handle medication and medical problems in these populations are requested by general practitioners [175].

\section{Demography and consequences for nursing homes}

With respect to uncertainties in population prognoses, we know for certain that the number and proportion of older people will increase substan- 
tially in all western societies. However, we know less about their future health, a factor of great importance for the demand for nursing home beds. The future demand for nursing home beds will also be influenced by sociocultural factors such as living alone and the closeness of the immediate family. This can be exemplified through differences between nearby countries such as Austria and the Czech Republic, with different populations living in nursing homes [112]. Sweden has one of the world's highest rates of older adults living alone. This proportion has previously increased for several years, but the increase has stopped in recent years [176]. Another future factor of uncertain importance in terms of the demand for nursing home beds is the consequences of immigration, resulting in an increasing proportion of older people with a different, foreign cultural background.

High costs for nursing home beds will probably drive the development so that as many older people as possible can stay in their own home for as long as possible. Thus, home care solutions will develop further. In the case of somatic disease or disability, it is often possible to adapt home environments and offer home health care so that an older person can live at home for a long time, even when living alone. However, dementia and cognitive impairment constitute a greater challenge, and are more difficult to compensate for in a home environment than somatic disabilities. For those who are cohabiting, a healthy spouse may compensate for cognitive impairment to a significant degree. For those who live alone, however, it is much more difficult to manage in their own home in the case of cognitive impairment.

As indicated previously, recent studies suggest that the year-specific incidence [94-97] and prevalence [98, 99] in high income countries is decreasing. This is believed to be due to several factors such as cardiovascular prevention and higher education level. Such a trend will be of great importance for future planning, as even a marginal upwards shift in dementia incidence can have a major impact on demand for nursing home beds. Unfortunately, there are no new breakthroughs in treatment options in sight for dementia.

With these considerations, it can be assumed that older people entering nursing homes in the future will have multiple, complex healthcare needs but also cognitive impairment. In the SHADES population it was estimated that $84 \%$ of the nursing home residents had cognitive impairment or dementia. In a near future almost all older people living in nursing homes will be cognitively impaired and the development described in Norwegian 
nursing homes with an increasing degree of cognitive impairment [30] is likely to continue. Another continuing trend is that older people will enter a nursing home even closer to the end of their life than today [177]. Consequently, the duration of residency will continue to decrease and there is likely to be an earlier transition from curative medicine to medicine that provides good palliative and end-of-life care. Furthermore, the overall demand for medical care for older people living in nursing homes will increase, meaning greater demands on physicians' time and need for clinical experience, and also more clinical guidelines for physicians who are supporting nursing homes.

\section{Comprehensive Geriatric Assessment (CGA)}

This thesis deals with four "giants of geriatrics". Falls ("instability") and cognitive impairment ("intellectual impairment") are among the original "giants of geriatrics" described by Isaacs [16]. Frailty, suggested by other authors as a "giant of geriatrics" $[19,20]$ meets all four, and anaemia meets three of the features suggested by Isaacs in terms of what the "giants of geriatrics" have in common [18]. These "giants of geriatrics" are all frequently prevalent in nursing homes. All "giants of geriatrics" deserve special awareness in nursing home residents but also in the oldest populations in general. The Comprehensive Geriatric Assessment (CGA), established in acute geriatric hospital care, may present a way to find those "giants of geriatrics" outside hospitals as well $[178,179]$. 


\section{CONCLUSIONS}

The investigated "giants of geriatrics" in this thesis are all prevalent in nursing home residents.

Frailty, despite being a widely used concept, lacks a clear definition or an established assessment instrument. However, nursing home residents show a high frequency of comorbidity and polypharmacy, and high risks of falls, malnutrition and pressure ulcers. Items in the frequently used risk assessments for these conditions overlap each other, and some of these items are of greater importance in rating the "frailty and need for care", as defined in SHADES.

Anaemia is frequently prevalent in nursing home residents. Using WHO limits, means an anaemia frequency of more than half of the men and one third of the women. WHO limits ( $<120 \mathrm{~g} / \mathrm{L}$ for women, $<130 \mathrm{~g} / \mathrm{L}$ for men) seem applicable for a nursing population. Different limits for women and men are supported by the fact that anaemia in men is associated with higher mortality. Hb decline is also associated with higher mortality. Decline is not predicted by previous levels. Consequently, regular control and comparisons with earlier values are recommended.

The fall risk is high in virtually all nursing home residents, and the majority of this population have fallen during the last year. In SHADES there was an association between falls during the last year and regular use of non-benzodiazepine hypnotics. These drugs were also associated with serious falls during the next 6 months in the older group. The association found between falls and regular use of a widely used hypnotic drug class deserves attention and further investigation. The results also highlight a need for more knowledge on suitable drug treatment strategies for the oldest, emphasize the focus on non-pharmacologic treatment as first line action in the case of insomnia, and open up fields for non-sedative alternatives, such as melatonin, and novel therapies. In addition, further attention to fall prevention work in nursing home environments is important.

Cognitive impairment is common in nursing homes residents, is often overseen, and demands greater attention. More than four out of five nursing home residents have a cognitive impairment, but dementia is usually 
previously diagnosed in only half of these. It is previously known that a missing dementia diagnosis has several consequences. Besides the fact that anti-dementia drug treatment is not considered, there is a risk of less awareness of possible inappropriate drugs, there may be inferior interaction and understanding between residents and caregivers, and a dementia diagnosis also has prognostic implications. The present results suggest that un-noted cognitive impairment may indicate other underlying potentially treatable conditions such as heart failure. Cognitive impairment should also lead to increased awareness of risks of malnutrition and pressure ulcers, as these are similar to the risks for those with diagnosed dementia. In clinical practice, these findings highlight the need to pay increased attention to signs of cognitive impairment in nursing home residents.

As these studied "giants of geriatrics" are common in a nursing home population, they need to be kept in mind at medical follow-ups. According to the present results, regular follow-ups in nursing homes are proposed to include blood count, drug review and cognitive evaluation. In the case of cognitive impairment, exclusion of underlying disease such as heart failure should be considered. 


\section{IMPLICATIONS FOR FUTURE STUDIES}

Based on the findings of this thesis, several areas of interest for future research have been identified.

Overall, few studies found on anaemia, falls and prevalence of cognitive impairment have been performed in nursing home populations, leaving an area for future research.

Frailty is a topic where there is a lack of knowledge and a need for research regarding definition, assessments, prevention and treatment. Nursing home populations are suitable for such studies.

Anaemia of unknown origin constitutes one third of anaemia cases in older populations such as nursing home residents. Consequently, there is a need for more research on causes of anaemia and possible treatment options in these populations.

Future research on associations between fall risk and non-benzodiazepine hypnotics is suggested, especially among the oldest. A large register study combining data on drug prescription and occurred hospitalization or emergency visits due to fall injuries would be of interest.

There is also a considerable need for further knowledge about associations between cognitive impairment and underlying morbidity including the relationship between frailty and cognitive impairment in nursing home populations.

Finally, in the rapidly growing oldest population aged over 85-90 years there is a general lack of knowledge and a need for future studies on epidemiology, morbidity and suitable medication according to compounds as well as doses. 


\section{ACKNOWLEDGEMENTS}

I would like to express my sincere gratitude to everyone who has helped me complete this thesis. I especially would like to thank:

... my main supervisor Jan Marcusson. You have patiently encouraged me and challenged me during this long journey. On several occasions when I felt like I was stuck in my mind and thinking about giving up this research project, you have shown that you believe in me and have given me the exact encouragement that I needed.

... my early co-supervisor Sigvard Mölstad. You took the initiative for SHADES, you got me involved from the very beginning, you helped me see my possibilities and you encouraged me to become a PhD student.

... my later co-supervisor Staffan Hägg. Having you nearby and getting your frequent positive and encouraging thoughts and feedback during the last few years has meant so much for me.

... my other co-authors in SHADES, especially Marie Ernsth Bravell, first author of paper I, for inspiration and statistical guidance, Carl Johan Östgren and Patrik Midlöv, co-authors of all papers, for so much feedback grounded in wisdom and experience, and Christina Lannering also for your patient support with all my questions on the SHADES data.

... statisticians Bo Rolander and Mats Nilsson at Futurum for your patient support with all my frequent, sometimes complicated and sometimes banal, questions.

... all the researchers and colleagues at the Department of Geriatrics in Linköping for involving me in your group, and the research colleagues and other personnel at Futurum for encouraging talks and new inspiration during coffee breaks. 
... my employer Region Jönköping County for giving me the research opportunity and my managers during that period, Wille Alstermark, Ann-Marie Schaffrath and Agneta Ståhl, for encouragement during the first few years, and Indira Liesto for encouragement in recent years, and especially for giving me the time to finish this work over the last couple of months by taking on an increased workload, despite a strained work situation at our clinic.

... all my colleagues and co-workers at the Geriatric Clinic at Ryhov County Hospital over the course of more than 20 years. Together, you have all created an environment with great compassion for the needs of the oldest patients. I am so grateful for all those years and I hope to still be a part of your valuable team in the future.

... Futurum, the Academy for Health and Care in Region Jönköping County for financial support, and the Medical Research Council of Southeast Sweden (FORSS) for financial support for SHADES.

... the SHADES study nurses, the nursing home staff in the included nursing homes and the study participants who all contributed to SHADES and made the SHADES data collection possible.

... my late parents; my father Åke who died early but contributed in forming me during my first 22 years, and my mother Birgit who passed away 2016, but has encouraged me so much during my whole life.

... my close family, Andreas, Fredrik, Magnus, Samuel and Elina, Mikaela and Lukas, who all mean more to me than you can imagine and I usually express, and above all my beloved Ingela for sharing so many years of my life and still always taking care of me, despite all my years of stress, tiredness and sometimes peculiar priorities. 


\section{REFERENCES}

1. Population Reference Bureau. 2018 World Population Data Sheet:

Population Reference Bureau; 2018 [cited 201920 March]. Available

from:

https://www.prb.org/wp-content/uploads/2018/o8/2018 WPDS.pdf.

2. Statistics Sweden. Demographic reports 2018:1. The future population of

Sweden 2018-2070: Statistics Sweden, Department Population and

Wellfare; 2018 [cited 201920 March]. Available from:

https://www.scb.se/contentassets/b3973c6465b446a690aec868d8b674 73/be0401_2018i70_br be51br1801.pdf.

3. Rechel B, Grundy E, Robine JM, Cylus J, Mackenbach JP, Knai C, et al. Ageing in the European Union. Lancet. 2013;381(9874):1312-22.

4. Parker MG, Thorslund M. Health trends in the elderly population: getting better and getting worse. Gerontologist. 2007;47(2):150-8.

5. Gruenberg EM. The failures of success. Milbank Mem Fund Q Health Soc. 1977;55(1):3-24.

6. Kramer M. The rising pandemic of mental disorders and associated chronic diseases and disabilities. Acta Psychiatr Scand. 1980;62(S285):382-97.

7. Fries JF. Aging, natural death, and the compression of morbidity. N Engl J Med. 1980;303(3):130-5.

8. Fries JF. Measuring and monitoring success in compressing morbidity. Ann Intern Med. 2003;139(5 Pt 2):455-9.

9. Manton KG. Changing concepts of morbidity and mortality in the elderly population. Milbank Mem Fund Q Health Soc. 1982;60(2):183-244.

10. OECD. Projecting OECD Health and Long-Term Care Expenditures. 2006.

11. OECD. Hospital beds (indicator) 2019 [cited 201920 March]. Available from: https://data.oecd.org/healtheqt/hospital-beds.htm.

12. Collerton J, Davies K, Jagger C, Kingston A, Bond J, Eccles MP, et al. Health and disease in 85 year olds: baseline findings from the Newcastle 85+ cohort study. BMJ. 2009;339:b4904.

13. Nägga K, Dong HJ, Marcusson J, Skoglund SO, Wressle E. Health-related factors associated with hospitalization for old people: comparisons of elderly aged 85 in a population cohort study. Arch Gerontol Geriatr. 2012;54(2):391-7.

14. Nascher I. Geriatrics. N Y Med J. 1909;90:358-9.

15. Nascher I. Geriatrics. The Diseases of Old Age and their Treatment. Philadelphia: P Blakiston's Son \& Co; 1914.

16. Isaacs B. An introduction to geriatrics. London: Ballière, Tindall and Cassel; 1965.

17. Isaacs B. The Giants of Geriatrics: A Study of Symptoms in Old Age: University of Birmingham; 1976.

18. Isaacs B. The Challenge of Geriatric Medicine. Oxford: Oxford University Press; 1992.

19. Morley JE. Frailty and Sarcopenia: The New Geriatric Giants. Rev Invest Clin. 2016;68(2):59-67. 
20. Panza F, Lozupone M, Solfrizzi V, Sardone R, Dibello V, Di Lena L, et al. Different Cognitive Frailty Models and Health- and Cognitive-related Outcomes in Older Age: From Epidemiology to Prevention. J Alzheimers Dis. 2018;62(3):993-1012.

21. Foltyn P. Ageing, dementia and oral health. Aust Dent J. 2015;60 Suppl 1:86-94.

22. Katz PR. An international perspective on long term care: focus on nursing homes. Journal of the American Medical Directors Association. 2011;12(7):487-92 e1.

23. Freedman VA, Crimmins E, Schoeni RF, Spillman BC, Aykan H, Kramarow $\mathrm{E}$, et al. Resolving inconsistencies in trends in old-age disability: report from a technical working group. Demography. 2004;41(3):417-41.

24. Tolson D, Rolland Y, Katz PR, Woo J, Morley JE, Vellas B. An international survey of nursing homes. Journal of the American Medical Directors Association. 2013;14(7):459-62.

25. Sanford AM, Orrell M, Tolson D, Abbatecola AM, Arai H, Bauer JM, et al. An international definition for "nursing home". Journal of the American Medical Directors Association. 2015;16(3):181-4.

26. National Board of Health and Welfare. Statistik om särskilt boende: Socialstyrelsen; 2016 [cited 201920 March]. 2016-12-5:[Available from: http://www.socialstyrelsen.se/Lists/Artikelkatalog/Attachments/20404 /2016-12-5.pdf.

27. National Board of Health and Welfare. Äldre - vård och omsorg år 2000 2001 [cited $201920 \mathrm{March}$ ]. Available from:

https://www.socialstyrelsen.se/Lists/Artikelkatalog/Attachments/11616/ 2001-44-3.pdf.

28. National Board of Health and Welfare. Äldre - vård och omsorg år 2005 2006 [cited $201920 \mathrm{March}$ ]. Available from:

https://www.socialstyrelsen.se/Lists/Artikelkatalog/Attachments/9784/ 2006-44-3 2006443.pdf.

29. National Board of Health and Welfare. Äldre - Vård och omsorg den 1 november 20102011 [cited $201920 \mathrm{March}$ ]. Available from: http://www.socialstyrelsen.se/Lists/Artikelkatalog/Attachments/18455/ 2011-10-10.pdf.

30. Helvik AS, Engedal K, Benth JS, Selbaek G. Prevalence and Severity of Dementia in Nursing Home Residents. Dement Geriatr Cogn Disord. 2015;40(3-4):166-77.

31. Morley JE, Caplan G, Cesari M, Dong B, Flaherty JH, Grossberg GT, et al. International survey of nursing home research priorities. Journal of the American Medical Directors Association. 2014;15(5):309-12.

32. Vaupel JW, Manton KG, Stallard E. The impact of heterogeneity in individual frailty on the dynamics of mortality. Demography. 1979;16(3):439-54.

33. Rodriguez-Manas L, Feart C, Mann G, Vina J, Chatterji S, Chodzko-Zajko W, et al. Searching for an operational definition of frailty: a Delphi method based consensus statement: the frailty operative definitionconsensus conference project. J Gerontol A Biol Sci Med Sci. 2013;68(1):62-7.

34. Morley JE, Vellas B, van Kan GA, Anker SD, Bauer JM, Bernabei R, et al. Frailty consensus: a call to action. Journal of the American Medical Directors Association. 2013;14(6):392-7. 
35. Fried LP, Tangen CM, Walston J, Newman AB, Hirsch C, Gottdiener J, et al. Frailty in Older Adults: Evidence for a Phenotype. The Journals of Gerontology Series A: Biological Sciences and Medical Sciences. 2001;56(3):M146-M57.

36. Rockwood K, Song X, MacKnight C, Bergman H, Hogan DB, McDowell I, et al. A global clinical measure of fitness and frailty in elderly people. CMAJ : Canadian Medical Association journal = journal de l'Association medicale canadienne. 2005;173(5):489-95.

37. Rockwood K, Abeysundera MJ, Mitnitski A. How should we grade frailty in nursing home patients? Journal of the American Medical Directors Association. 2007;8(9):595-603.

38. Gobbens RJ, Luijkx KG, Wijnen-Sponselee MT, Schols JM. In search of an integral conceptual definition of frailty: opinions of experts. Journal of the American Medical Directors Association. 2010;11(5):338-43.

39. Gobbens RJ, van Assen MA, Luijkx KG, Schols JM. Testing an integral conceptual model of frailty. J Adv Nurs. 2012;68(9):2047-60.

40. Buta BJ, Walston JD, Godino JG, Park M, Kalyani RR, Xue QL, et al. Frailty assessment instruments: Systematic characterization of the uses and contexts of highly-cited instruments. Ageing Res Rev. 2016;26:53-61.

41. Patel KV. Epidemiology of anemia in older adults. Semin Hematol. 2008;45(4):210-7.

42. Gaskell H, Derry S, Andrew Moore R, McQuay HJ. Prevalence of anaemia in older persons: systematic review. BMC geriatrics. 2008;8:1.

43. Callera F, Callera AF, da Silva AM, Rosa ES. Prevalence of anemia in a sample of elderly southeastern Brazilians. Rev Bras Hematol Hemoter. 2015;37(1):43-7.

44. Salive ME, Cornoni-Huntley J, Guralnik JM, Phillips CL, Wallace RB, Ostfeld AM, et al. Anemia and hemoglobin levels in older persons: relationship with age, gender, and health status. J Am Geriatr Soc. 1992;40(5):489-96.

45. Pang WW, Schrier SL. Anemia in the elderly. Current opinion in hematology. 2012;19(3):133-40.

46. World Health Organization. Nutritional anaemias. Report of a WHO scientific group. 1968 0512-3054.

47. Beutler E, Waalen J. The definition of anemia: what is the lower limit of normal of the blood hemoglobin concentration? Blood. 2006;107(5):1747-50.

48. Mindell J, Moody A, Ali A, Hirani V. Using longitudinal data from the Health Survey for England to resolve discrepancies in thresholds for haemoglobin in older adults. Br J Haematol. 2013;160(3):368-76.

49. Nilsson-Ehle H, Jagenburg R, Landahl S, Svanborg A. Blood haemoglobin declines in the elderly: implications for reference intervals from age 70 to 88. Eur J Haematol. 2000;65(5):297-305.

50. Andres E, Serraj K, Federici L, Vogel T, Kaltenbach G. Anemia in elderly patients: new insight into an old disorder. Geriatr Gerontol Int. 2013;13(3):519-27.

51. Patel KV, Longo DL, Ershler WB, Yu B, Semba RD, Ferrucci L, et al. Haemoglobin concentration and the risk of death in older adults: differences by race/ethnicity in the NHANES III follow-up. Br J Haematol. 2009;145(4):514-23. 
52. Shahani S, Braga-Basaria M, Maggio M, Basaria S. Androgens and erythropoiesis: Past and present. J Endocrinol Invest. 2009;32(8):70416.

53. Guralnik JM, Eisenstaedt RS, Ferrucci L, Klein HG, Woodman RC. Prevalence of anemia in persons 65 years and older in the United States: evidence for a high rate of unexplained anemia. Blood. 2004;104(8):2263-8.

54. Izaks GJ, Westendorp RG, Knook DL. The definition of anemia in older persons. J Am Med Assoc. 1999;281(18):1714-7.

55. Penninx BW, Pahor M, Woodman RC, Guralnik JM. Anemia in old age is associated with increased mortality and hospitalization. J Gerontol A Biol Sci Med Sci. 2006;61(5):474-9.

56. Riva E, Tettamanti M, Mosconi P, Apolone G, Gandini F, Nobili A, et al. Association of mild anemia with hospitalization and mortality in the elderly: the Health and Anemia population-based study. Haematologica. 2009;94(1):22-8.

57. Robinson B, Artz AS, Culleton B, Critchlow C, Sciarra A, Audhya P. Prevalence of anemia in the nursing home: contribution of chronic kidney disease. J Am Geriatr Soc. 2007;55(10):1566-70.

58. Resnick B, Sabol V, Galik E, Gruber-Baldini AL. The impact of anemia on nursing home residents. Clin Nurs Res. 2010;19(2):113-30.

59. Schnelle J, Osterweil D, Globe D, Sciarra A, Audhya P, Barlev A. Chronic kidney disease, anemia, and the association between chronic kidney disease-related anemia and activities of daily living in older nursing home residents. J Am Med Dir Assoc. 2009;10(2):120-6.

6o. Binder EF, White HK, Resnick B, McClellan WM, Lei L, Ouslander JG. A prospective study of outcomes of nursing home residents with chronic kidney disease with and without anemia. J Am Geriatr Soc. 2012;60(5):877-83.

61. Merchant AA, Roy CN. Not so benign haematology: anaemia of the elderly. Br J Haematol. 2012;156(2):173-85.

62. World Health Organization. WHO Global Report on Falls Prevention in Older Age France2007 [cited 201920 March]. Available from: http://www.who.int/ageing/publications/Falls_prevention7March.pdf?u $\underline{a=1}$.

63. Panel on Prevention of Falls in Older Persons AGSaBGS. Summary of the Updated American Geriatrics Society/British Geriatrics Society Clinical Practice Guideline for Prevention of Falls in Older Persons. J Am Geriatr Soc. 2011;59(1):148-57.

64. Nazir A, Mueller C, Perkins A, Arling G. Falls and nursing home residents with cognitive impairment: new insights into quality measures and interventions. J Am Med Dir Assoc. 2012;13(9):819.e1-6.

65. Becker C, Rapp K. Fall prevention in nursing homes. Clin Geriatr Med. 2010;26(4):693-704.

66. Pandya N, Bookhart B, Mody SH, Funk Orsini PA, Reardon G. Study of anemia in long-term care (SALT): prevalence of anemia and its relationship with the risk of falls in nursing home residents. Curr Med Res Opin. 2008;24(8):2139-49.

67. Maher RL, Hanlon J, Hajjar ER. Clinical consequences of polypharmacy in elderly. Expert opinion on drug safety. 2014;13(1):57-65. 
68. Boyd CM, Darer J, Boult C, Fried LP, Boult L, Wu AW. Clinical practice guidelines and quality of care for older patients with multiple comorbid diseases: implications for pay for performance. Jama. 2005;294(6):71624.

69. Corsonello A, Pedone C, Incalzi RA. Age-related pharmacokinetic and pharmacodynamic changes and related risk of adverse drug reactions. Current medicinal chemistry. 2010;17(6):571-84.

70. Konrat C, Boutron I, Trinquart L, Auleley GR, Ricordeau P, Ravaud P. Underrepresentation of elderly people in randomised controlled trials. The example of trials of 4 widely prescribed drugs. PloS one. 2012;7(3):e33559.

71. The Swedish Council on Technology Assessment in Health Care. Äldres läkemedelsanvändning - hur kan den förbättras? 2009.

72. National Board of Health and Welfare (Socialstyrelsen). Indicators for evaluating the quality in medication of elderly (in Swedish; Indikatorer för utvärdering av kvaliteten i äldres läkemedelsterapi). 2004. 2003-11020.

73. National Board of Health and Welfare (Socialstyrelsen). Indicators of good pharmaceutical treatment in elderly (In Swedish; Indikatorer för god läkemedelsterapi hos äldre) 2010 [cited 201920 March]. Available from: http://www.socialstyrelsen.se/Lists/Artikelkatalog/Attachments/18085/ 2010-6-29.pdf.

74. National Board of Health and Welfare (Socialstyrelsen). Indicators of good pharmaceutical treatment in elderly (In Swedish; Indikatorer för god läkemedelsterapi hos äldre) 2017 [cited $201920 \mathrm{March}$ ]. Available from: https://www.socialstyrelsen.se/Lists/Artikelkatalog/Attachments/20644 2017-6-7.pdf.

75. Beers MH, Ouslander JG, Rollingher I, Reuben DB, Brooks J, Beck JC. Explicit criteria for determining inappropriate medication use in nursing home residents. UCLA Division of Geriatric Medicine. Arch Intern Med. 1991;151(9):1825-32.

76. Beers MH. Explicit criteria for determining potentially inappropriate medication use by the elderly. An update. Arch Intern Med. 1997;157(14):1531-6.

77. Fick DM, Cooper JW, Wade WE, Waller JL, Maclean JR, Beers MH. Updating the Beers criteria for potentially inappropriate medication use in older adults: results of a US consensus panel of experts. Arch Intern Med. 2003;163(22):2716-24.

78. The American Geriatrics Society 2012 Beers Criteria Update Expert Panel. American Geriatrics Society Updated Beers Criteria for Potentially Inappropriate Medication Use in Older Adults. J Am Geriatr Soc. 2012;60(4):616-31.

79. The American Geriatrics Society 2015 Beers Criteria Update Expert Panel. American Geriatrics Society 2015 Updated Beers Criteria for Potentially Inappropriate Medication Use in Older Adults. J Am Geriatr Soc. 2015;63(11):2227-46.

80. Gallagher P, Ryan C, Byrne S, Kennedy J, O'Mahony D. STOPP (Screening Tool of Older Person's Prescriptions) and START (Screening Tool to Alert doctors to Right Treatment). Consensus validation. Int J Clin Pharmacol Ther. 2008;46(2):72-83. 
81. O'Mahony D, O'Sullivan D, Byrne S, O'Connor MN, Ryan C, Gallagher P. STOPP/START criteria for potentially inappropriate prescribing in older people: version 2. Age and Ageing. 2015;44(2):213-8.

82. Hartikainen S, Lonnroos E, Louhivuori K. Medication as a risk factor for falls: critical systematic review. J Gerontol A Biol Sci Med Sci. 2007;62(10):1172-81.

83. Woolcott JC, Richardson KJ, Wiens MO, Patel B, Marin J, Khan KM, et al. Meta-analysis of the impact of 9 medication classes on falls in elderly persons. Arch Intern Med. 2009;169(21):1952-60.

84. Park H, Satoh H, Miki A, Urushihara H, Sawada Y. Medications associated with falls in older people: systematic review of publications from a recent 5-year period. Eur J Clin Pharmacol. 2015;71(12):1429-40.

85. Cox CA, van Jaarsveld HJ, Houterman S, van der Stegen JC, Wasylewicz AT, Grouls RJ, et al. Psychotropic Drug Prescription and the Risk of Falls in Nursing Home Residents. J Am Med Dir Assoc. 2016;17(12):1089-93.

86. Rojas-Fernandez C, Dadfar F, Wong A, Brown SG. Use of fall risk increasing drugs in residents of retirement villages: a pilot study of long term care and retirement home residents in Ontario, Canada. BMC Res Notes. 2015;8:568.

87. Olazaran J, Valle D, Serra JA, Cano P, Muniz R. Psychotropic medications and falls in nursing homes: a cross-sectional study. J Am Med Dir Assoc. 2013;14(3):213-7.

88. Dolder C, Nelson M, McKinsey J. Use of non-benzodiazepine hypnotics in the elderly: are all agents the same? CNS drugs. 2007;21(5):389-405.

89. Fastbom J, Johnell K. National indicators for quality of drug therapy in older persons: the Swedish experience from the first 10 years. Drugs Aging. 2015;32(3):189-99.

90. Schwartz S. Sleep Disorders. In: Wehling M, editor. Drug Therapy for the Elderly. Wien: Springer-Verlag; 2013. p. 215-27.

91. Johnell K, Fastbom J. Comparison of prescription drug use between community-dwelling and institutionalized elderly in Sweden. Drugs Aging. 2012;29(9):751-8.

92. Berry SD, Lee Y, Cai S, Dore DD. Nonbenzodiazepine sleep medication use and hip fractures in nursing home residents. JAMA Intern Med. 2013;173JAMA Intern Med(9):754-61.

93. Prince M, Bryce R, Albanese E, Wimo A, Ribeiro W, Ferri CP. The global prevalence of dementia: a systematic review and metaanalysis.

Alzheimers Dement. 2013;9(1):63-75 e2.

94. Qiu C, von Strauss E, Bäckman L, Winblad B, Fratiglioni L. Twenty-year changes in dementia occurrence suggest decreasing incidence in central Stockholm, Sweden. Neurology. 2013;80(20):1888-94.

95. Schrijvers EMC, Verhaaren BFJ, Koudstaal PJ, Hofman A, Ikram MA, Breteler MMB. Is dementia incidence declining? Neurology. 2012;78(19):1456-63.

96. Satizabal CL, Beiser AS, Chouraki V, Chêne G, Dufouil C, Seshadri S. Incidence of Dementia over Three Decades in the Framingham Heart Study. New England Journal of Medicine. 2016;374(6):523-32.

97. Grasset L, Brayne C, Joly P, Jacqmin-Gadda H, Peres K, Foubert-Samier A, et al. Trends in dementia incidence: Evolution over a 10-year period in France. Alzheimers Dement. 2016;12(3):272-80. 
98. Matthews FE, Arthur A, Barnes LE, Bond J, Jagger C, Robinson L, et al. A two-decade comparison of prevalence of dementia in individuals aged 65 years and older from three geographical areas of England: results of the Cognitive Function and Ageing Study I and II. The Lancet. 2013;382(9902):1405-12.

99. Skoog I, Börjesson-Hanson A, Kern S, Johansson L, Falk H, Sigström R, et al. Decreasing prevalence of dementia in 85-year olds examined 22 years apart: the influence of education and stroke. Sci Rep. 2017;7(1):6136.

100.Mathillas J, Lövheim H, Gustafson Y. Increasing prevalence of dementia among very old people. Age Ageing. 2011;40(2):243-9.

101. Rocca WA, Petersen RC, Knopman DS, Hebert LE, Evans DA, Hall KS, et al. Trends in the incidence and prevalence of Alzheimer's disease, dementia, and cognitive impairment in the United States. Alzheimers Dement. 2011;7(1):80-93.

102.Prince M, Ali GC, Guerchet M, Prina AM, Albanese E, Wu YT. Recent global trends in the prevalence and incidence of dementia, and survival with dementia. Alzheimers Res Ther. 2016;8(1):23.

103.Lang L, Clifford A, Wei L, Zhang D, Leung D, Augustine G, et al. Prevalence and determinants of undetected dementia in the community: a systematic literature review and a meta-analysis. BMJ Open. 2017;7(2):e011146.

104.Connolly A, Gaehl E, Martin H, Morris J, Purandare N. Underdiagnosis of dementia in primary care: variations in the observed prevalence and comparisons to the expected prevalence. Aging Ment Health. 2011;15(8):978-84.

105. Social Protection Committee and the European Commission. Adequate social protection for long-term care needs in an ageing society Luxembourg: European Union; 2014 [cited 201920 March]. Available from: Available from:

https://ec.europa.eu/social/BlobServlet?docId=12808\&langId=en.

106. Seitz D, Purandare N, Conn D. Prevalence of psychiatric disorders among older adults in long-term care homes: a systematic review. Int Psychogeriatr. 2010;22(7):1025-39.

107. Onder G, Carpenter I, Finne-Soveri H, Gindin J, Frijters D, Henrard JC, et al. Assessment of nursing home residents in Europe: the Services and Health for Elderly in Long TERm care (SHELTER) study. BMC Health Serv Res. 2012;12:5.

108.National Board of Health and Welfare. Demenssjukdomarnas samhällskostnader i Sverige 2012: Socialstyrelsen; 2014 [cited 201920 March]. 2014-6-3:[Available from: https://www.socialstyrelsen.se/Lists/Artikelkatalog/Attachments/19444 2014-6-3.pdf.

109.Björk S, Juthberg C, Lindkvist M, Wimo A, Sandman P-O, Winblad B, et al. Exploring the prevalence and variance of cognitive impairment, pain, neuropsychiatric symptoms and ADL dependency among persons living in nursing homes; a cross-sectional study. BMC Geriatr. 2016;16(1):154.

110. Roen I, Selbaek G, Kirkevold O, Engedal K, Testad I, Bergh S. Resourse Use and Disease Couse in dementia - Nursing Home (REDIC-NH), a longitudinal cohort study; design and patient characteristics at admission to Norwegian nursing homes. BMC Health Serv Res. 2017;17(1):365. 
111. Lithgow S, Jackson GA, Browne D. Estimating the prevalence of dementia: cognitive screening in Glasgow nursing homes. Int $\mathrm{J}$ Geriatr Psychiatry. 2012;27(8):785-91.

112. Auer SR, Hofler M, Linsmayer E, Berankova A, Prieschl D, Ratajczak P, et al. Cross-sectional study of prevalence of dementia, behavioural symptoms, mobility, pain and other health parameters in nursing homes in Austria and the Czech Republic: results from the DEMDATA project. BMC Geriatr. 2018;18(1):178.

113. Singer C, Luxenberg J. Diagnosing dementia in long-term care facilities. J Am Med Dir Assoc. 2003;4(6 Suppl):S134-40.

114. Folstein MF, Folstein SE, McHugh PR. "Mini-mental state". A practical method for grading the cognitive state of patients for the clinician. J Psychiatr Res. 1975;12(3):189-98.

115. Tombaugh TN, McIntyre NJ. The mini-mental state examination: a comprehensive review. J Am Geriatr Soc. 1992;40(9):922-35.

116. Kvitting AS, Fällman K, Wressle E, Marcusson J. Age-Normative MMSE Data for Older Persons Aged 85 to 93 in a Longitudinal Swedish Cohort. J Am Geriatr Soc. 2018;o(o).

117. Daniels LB, Laughlin GA, Kritz-Silverstein D, Clopton P, Chen WC, Maisel $\mathrm{AS}$, et al. Elevated natriuretic peptide levels and cognitive function in community-dwelling older adults. Am J Med. 2011;124(7):670 e1-8.

118. Feinkohl I, Sattar N, Welsh P, Reynolds RM, Deary IJ, Strachan MW, et al. Association of N-terminal pro-brain natriuretic peptide with cognitive function and depression in elderly people with type 2 diabetes. PloS one. 2012;7(9):e44569.

119. van Vliet P, Sabayan B, Wijsman LW, Poortvliet RKE, Mooijaart SP, de Ruijter W, et al. NT-proBNP, blood pressure, and cognitive decline in the oldest old: The Leiden 85-plus Study. Neurology. 2014;83(13):1192-9.

120.Bell CL, Lee AS, Tamura BK. Malnutrition in the nursing home. Curr Opin Clin Nutr Metab Care. 2015;18(1):17-23.

121. World Health Organization. ATC - Structure and principles: WHO Collaborating Centre for Drug Statistics Methodology; [updated 2011o3-25; cited 201920 March]. Available from: https://www.whocc.no/atc/structure and principles/.

122. World Health Organization. International statistical classification of diseases and related health problems (ICD-10). 10th Ed ed. Geneva: WHO; 1992.

123. Alexopoulos GS, Abrams RC, Young RC, Shamoian CA. Cornell Scale for Depression in Dementia. Biol Psychiatry. 1988;23(3):271-84.

124. Downton JH. Falls in the Elderly. London: Edward Arnold; 1993. p. 128-30. 125. Ek AC, Unosson M, Bjurulf P. The modified Norton scale and the nutritional state. Scandinavian journal of caring sciences. 1989;3(4):1837.

126. Rubenstein LZ, Harker JO, Salva A, Guigoz Y, Vellas B. Screening for undernutrition in geriatric practice: developing the short-form mininutritional assessment (MNA-SF). J Gerontol A Biol Sci Med Sci. 2001;56(6):M366-72.

127. SNAC. SNAC-K Vårdsystem - Vårdsystem. The Swedish National Study on Aging and Care - Kungsholmen [cited 201920 March]. Available from: https://snacsweden.files.wordpress.com/2013/11/undersc3b6kningsprot okoll.pdf. 
128. Swedish Agency for Health Technology Assessment and Assessment of Social Services. Methods to Estimate and Measure Renal Function (Glomerular Filtration Rate) - A Systematic Review 2013 [cited 201920 March]. Available from: http://www.sbu.se/upload/Publikationer/Contento/1/Njurfunktion/Nju rfunktion.pdf.

129. Bolmsjö BB, Mölstad S, Gallagher M, Chalmers J, Östgren CJ, Midlöv P. Risk factors and consequences of decreased kidney function in nursing home residents: A longitudinal study. Geriatrics \& gerontology international. 2017;17(5):791-7.

130.Bolmsjö BB, Mölstad S, Östgren CJ, Midlöv P. Prevalence and treatment of heart failure in Swedish nursing homes. BMC geriatrics. 2013;13:118.

131. Hallgren J, Ernsth Bravell M, Mölstad S, Östgren CJ, Midlöv P, Dahl Aslan AK. Factors associated with increased hospitalisation risk among nursing home residents in Sweden: a prospective study with a three-year followup. Int J Older People Nurs. 2016;11(2):130-9.

132. Lannering C, Ernsth Bravell M, Midlöv P, Östgren CJ, Mölstad S. Factors related to falls, weight-loss and pressure ulcers - more insight in risk assessment among nursing home residents. Journal of clinical nursing. 2016.

133. Midlöv P, Andersson M, Östgren CJ, Mölstad S. Depression and use of antidepressants in Swedish nursing homes: a 12-month follow-up study. Int Psychogeriatr. 2014;26(4):669-75.

134. Samefors M, Östgren CJ, Mölstad S, Lannering C, Midlöv P, Tengblad A. Vitamin D deficiency in elderly people in Swedish nursing homes is associated with increased mortality. European journal of endocrinology / European Federation of Endocrine Societies. 2014;170(5):667-75.

135. Modig S, Lannering C, Östgren CJ, Mölstad S, Midlöv P. The assessment of renal function in relation to the use of drugs in elderly in nursing homes; a cohort study. BMC geriatrics. 2011;11:1.

136. Olofsson M, Lindgren PE, Östgren CJ, Midlöv P, Mölstad S. Colonization with Staphylococcus aureus in Swedish nursing homes: a cross-sectional study. Scand J Infect Dis. 2012;44(1):3-8.

137. Olofsson M, Toepfer M, Östgren CJ, Midlöv P, Matussek A, Lindgren PE, et al. Low level of antimicrobial resistance in Escherichia coli among Swedish nursing home residents. Scand J Infect Dis. 2013;45(2):117-23.

138. Borgström Bolmsjö B, Jakobsson U, Mölstad S, Östgren CJ, Midlöv P. The nutritional situation in Swedish nursing homes - a longitudinal study. Arch Gerontol Geriatr. 2015;60(1):128-33.

139. Rådholm K, Festin K, Falk M, Midlöv P, Mölstad S, Östgren CJ. Blood pressure and all-cause mortality: a prospective study of nursing home residents. Age Ageing. 2016;45(6):826-32.

140.Ahmed N, Mandel R, Fain MJ. Frailty: an emerging geriatric syndrome. Am J Med. 2007;120(9):748-53.

141. Pickering G. Frail elderly, nutritional status and drugs. Arch Gerontol Geriatr. 2004;38(2):174-80.

142. Morin L, Laroche ML, Vetrano DL, Fastbom J, Johnell K. Adequate, questionable, and inadequate drug prescribing for older adults at the end of life: a European expert consensus. European journal of clinical pharmacology. 2018. 
143. Panza F, Lozupone M, Logroscino G. Understanding frailty to predict and prevent dementia. The Lancet Neurology. 2019;18(2):133-4.

144. Barca ML, Engedal K, Laks J, Selbaek G. A 12 months follow-up study of depression among nursing-home patients in Norway. J Affect Disord. 2010;120(1-3):141-8.

145. Artz AS, Fergusson D, Drinka PJ, Gerald M, Gravenstein S, Lechich A, et al. Prevalence of anemia in skilled-nursing home residents. Arch Gerontol Geriatr. 2004;39(3):201-6.

146. Chan TC, Yap DY, Shea YF, Luk JK, Chan FH, Chu LW. Prevalence of anemia in Chinese nursing home older adults: implication of age and renal impairment. Geriatr Gerontol Int. 2013;13(3):591-6.

147. Landi F, Russo A, Danese P, Liperoti R, Barillaro C, Bernabei R, et al. Anemia status, hemoglobin concentration, and mortality in nursing home older residents. J Am Med Dir Assoc. 2007;8(5):322-7.

148. De Maria R, Ripamonti V, Sandri R, Ceretti AP, Ferratini M. The negative prognostic synergism of anemia and heart disease in female nursing home residents. Am J Cardiol. 2005;96(10):1460-2.

149. Kikuchi M, Inagaki T, Shinagawa N. Five-Year Survival of Older People with Anemia: Variation with Hemoglobin Concentration. J Am Geriatr Soc. 2001;49(9):1226-8.

150.Zakai NA, French B, Arnold AM, Newman AB, Fried LF, Robbins J, et al. Hemoglobin decline, function, and mortality in the elderly: the cardiovascular health study. Am J Hematol. 2013;88(1):5-9.

151. Sanger DJ. The Pharmacology and Mechanisms of Action of New Generation, Non-Benzodiazepine Hypnotic Agents. CNS drugs. 2004;18:9-15.

152. Gustafsson M, Karlsson S, Gustafson Y, Lövheim H. Psychotropic drug use among people with dementia--a six-month follow-up study. BMC Pharmacol Toxicol. 2013;14:56.

153. Levy HB. Non-benzodiazepine hypnotics and older adults: what are we learning about zolpidem? Expert Rev Clin Pharmacol. 2014;7(1):5-8.

154. Bakken MS, Engeland A, Engesaeter LB, Ranhoff AH, Hunskaar S, Ruths S. Risk of hip fracture among older people using anxiolytic and hypnotic drugs: a nationwide prospective cohort study. European journal of clinical pharmacology. 2014;70(7):873-80.

155. Allain H, Bentue-Ferrer D, Tarral A, Gandon JM. Effects on postural oscillation and memory functions of a single dose of zolpidem $5 \mathrm{mg}$, zopiclone $3.75 \mathrm{mg}$ and lormetazepam $1 \mathrm{mg}$ in elderly healthy subjects. A randomized, cross-over, double-blind study versus placebo. Eur J Clin Pharmacol. 2003;59(3):179-88.

156. Mets MA, Volkerts ER, Olivier B, Verster JC. Effect of hypnotic drugs on body balance and standing steadiness. Sleep Med Rev. 2010;14(4):25967.

157. Shuto H, Imakyure O, Matsumoto J, Egawa T, Jiang Y, Hirakawa M, et al. Medication use as a risk factor for inpatient falls in an acute care hospital: a case-crossover study. Br J Clin Pharmacol. 2010;69(5):53542.

158. Finkle WD, Der JS, Greenland S, Adams JL, Ridgeway G, Blaschke T, et al. Risk of fractures requiring hospitalization after an initial prescription for zolpidem, alprazolam, lorazepam, or diazepam in older adults. J Am Geriatr Soc. 2011;59(10):1883-90. 
159. Nyborg G, Brekke M, Straand J, Gjelstad S, Romøren M. Potentially inappropriate medication use in nursing homes: an observational study using the NORGEP-NH criteria. BMC geriatrics. 2017;17(1):220.

160.Ruths S, Straand J, Nygaard H. Psychotropic drug use in nursing homes diagnostic indications and variations between institutions. Eur J Clin Pharmacol. 2001;57(6):523-8.

161. Chen Y, Briesacher BA, Field TS, Tjia J, Lau DT, Gurwitz JH. Unexplained variation across US nursing homes in antipsychotic prescribing rates. Arch Intern Med. 2010;170(1):89-95.

162. Fleming J, Matthews FE, Brayne C. Falls in advanced old age: recalled falls and prospective follow-up of over-90-year-olds in the Cambridge City over-75s Cohort study. BMC Geriatr. 2008;8(1):6.

163. Jørgensen LB, Thorleifsson BM, Selbæk G, Šaltytė Benth J, Helvik A-S. Physical diagnoses in nursing home residents - is dementia or severity of dementia of importance? BMC Geriatr. 2018;18(1):254.

164. Vogels RL, Scheltens P, Schroeder-Tanka JM, Weinstein HC. Cognitive impairment in heart failure: a systematic review of the literature. Eur J Heart Fail. 2007;9(5):440-9.

165. Adelborg K, Horvath-Puho E, Ording A, Pedersen L, Toft Sørensen H, Henderson VW. Heart failure and risk of dementia: a Danish nationwide population-based cohort study. Eur J Heart Fail. 2017;19(2):253-60.

166. Raymond I, Groenning BA, Hildebrandt PR, Nilsson JC, Baumann M, Trawinski J, et al. The influence of age, sex and other variables on the plasma level of N-terminal pro brain natriuretic peptide in a large sample of the general population. Heart. 2003;89(7):745.

167. American Psychiatric Association MBFE, Harold Alan Pincus Diagnostic and Statistical Manual of Mental Disorders - Fourth Edition (DSM-IV): American Psychiatric Association, Washington D.C.; 1994.

168. American Psychiatric Association e. Diagnostic and Statistical Manual of Mental Disorders - Fourth Edition (DSM-5). $5^{\text {th }}$ edition ed: American Psychiatric Association, Washington D.C.; 2013.

169. Panza F, D'Introno A, Colacicco AM, Capurso C, Parigi AD, Capurso SA, et al. Cognitive frailty: Predementia syndrome and vascular risk factors. Neurobiol Aging. 2006;27(7):933-40.

170. Wallace LMK, Theou O, Godin J, Andrew MK, Bennett DA, Rockwood K. Investigation of frailty as a moderator of the relationship between neuropathology and dementia in Alzheimer's disease: a cross-sectional analysis of data from the Rush Memory and Aging Project. The Lancet Neurology. 2019;18(2):177-84.

171. Groom L, Avery AJ, Boot D, O'Neill C, Thornhill K, Brown K, et al. The impact of nursing home patients on general practitioners' workload. Br J Gen Pract. 2000;50(455):473-6.

172. Jacobs S. Addressing the problems associated with general practitioners' workload in nursing and residential homes: findings from a qualitative study. Br J Gen Pract. 2003;53(487):113-9.

173. Burgess S, Davis J, Morgans A. General practice and residential aged care: A qualitative study of barriers to access to care and the role of remuneration. Australas Med J. 2015;8(5):161-9.

174. Bolmsjö BB, Strandberg EL, Midlöv P, Brorsson A. "It is meaningful; I feel that I can make a difference" -A qualitative study about GPs' experiences of work at nursing homes in Sweden. BMC Fam Pract. 2015;16:111. 
175. Schuling J, Gebben H, Veehof LJ, Haaijer-Ruskamp FM. Deprescribing medication in very elderly patients with multimorbidity: the view of Dutch GPs. A qualitative study. BMC Fam Pract. 2012;13:56.

176. Shaw BA, Fors S, Fritzell J, Lennartsoon C, Agahi N. Who Lives Alone During Old Age? Trends in the Social and Functional Disadvantages of Sweden's Solitary Living Older Adults. Res Aging. 2018;40(9):815-38.

177. Schön P, Lagergren M, Kåreholt I. Rapid decrease in length of stay in institutional care for older people in Sweden between 2006 and 2012: results from a population-based study. Health \& social care in the community. 2015.

178. Parker SG, McCue P, Phelps K, McCleod A, Arora S, Nockels K, et al. What is Comprehensive Geriatric Assessment (CGA)? An umbrella review. Age Ageing. 2018;47(1):149-55.

179. Pilotto A, Cella A, Pilotto A, Daragjati J, Veronese N, Musacchio C, et al. Three Decades of Comprehensive Geriatric Assessment: Evidence Coming From Different Healthcare Settings and Specific Clinical Conditions. Journal of the American Medical Directors Association. 2017;18(2):192 e1- e11. 


\section{Publications}

The publications associated with this thesis have been removed for copyright reasons. For more details about these see:

http://urn.kb.se/resolve?urn=urn:nbn:se:liu:diva-155641 



\section{FACULTY OF MEDICINE AND HEALTH SCIENCES}

Linköping University Medical Dissertation No. 1674, 2019

Department of Clinical and Experimental Medicine

Linköping University

SE-581 83 Linköping, Sweden

www.liu.se 